\title{
ENVIRONMENTAL DETERMINANTS OF THREESPINE STICKLEBACK SPECIES PAIR EVOLUTION AND PERSISTENCE
}

\author{
by \\ CHAD INDAR ORMOND \\ B.Sc., Malaspina University-College, 2005

\section{A THESIS SUBMITTED IN PARTIAL FULFILLMENT OF THE REQUIREMENTS FOR THE DEGREE OF}

MASTER OF SCIENCE

in

THE FACULTY OF GRADUATE STUDIES

(Zoology)

\section{THE UNIVERSITY OF BRITISH COLUMBIA}

(Vancouver)

October 2010

(C) Chad Indar Ormond, 2010 


\begin{abstract}
Southwestern British Columbia is unique in that it is apparently the only place on Earth with sympatric species pairs of threespine stickleback (Gasterosteus aculeatus). As such, these species pairs are listed as endangered and are protected under Canada's Species at Risk Act. Historically these species pairs inhabited seven known lakes but their distribution is currently limited to five lakes in three watersheds. Within these lakes stickleback are found in two forms: benthic and limnetic. These species pairs are thought to have originated through a doubleinvasion process followed by character displacement. While this hypothesis is supported by morphology and genetics it does not take into account the environmental factors needed to support threespine stickleback in two separate microhabitats, which may be essential for their continued persistence. It is conceivable that the divergence and persistence of the threespine stickleback species pairs may be due in part to unique environmental characteristics of the lakes they inhabit, including physical lake characteristics, water chemistry, or biological productivity. Alternatively, divergence and persistence could be due to specific attributes of fish community structure or random colonization events unrelated to lake attributes. To establish this, I measured a number of abiotic (water chemistry, physical lake parameters) and biotic (food resources, macrophyte abundance) variables from both species pair and non-species pair threespine stickleback lakes in order to identify any factors that may discriminate species pair lakes from non-species pair lakes, thereby leading to a clearer understanding of their critical habitat. While I did not find any clear environmental differences between species pair and non-species pair lakes, my study suggests that a major determinant of the existence of stickleback species pairs is the community of fish present in the lakes and that nesting habitat heterogeneity and its influence on pre-mating reproductive barriers may be important to the persistence of these species pairs. My study provides a baseline to monitor the environments for all known species pair lakes and suggests that the fish assemblage in stickleback lakes may affect resource availability as strongly as the limnological attributes of the lakes themselves although predation may also be an important factor in the evolution of these species pairs.
\end{abstract}




\section{Table of Contents}

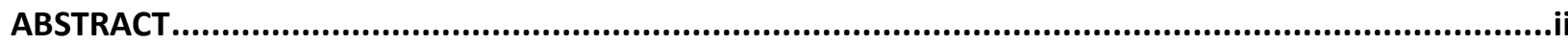

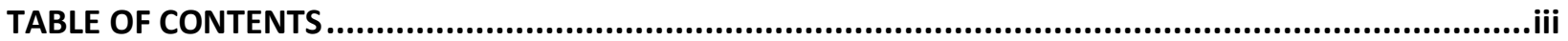

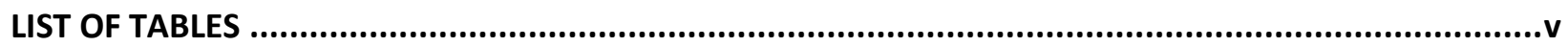

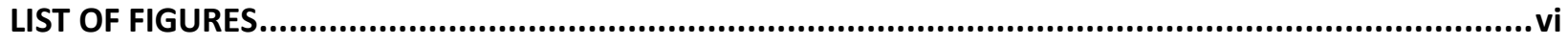

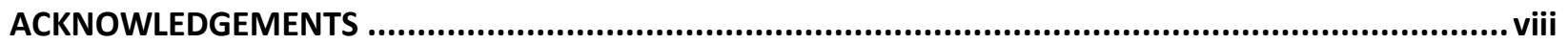

CHAPTER 1 - GENERAL INTRODUCTION

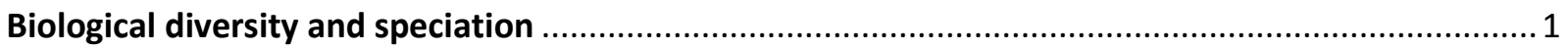

Habitat heterogeneity, speciation, and extinction ................................................................... 3

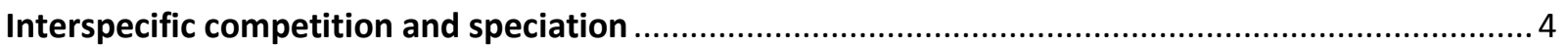

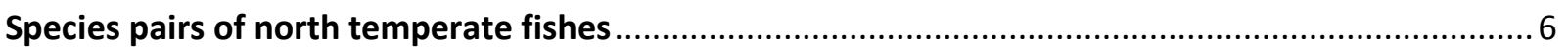

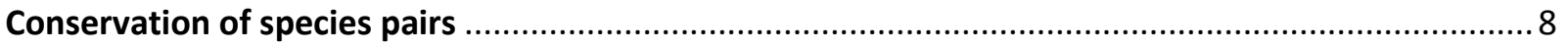

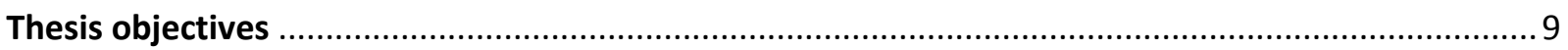

CHAPTER 2 - ENVIRONMENTAL DETERMINANTS OF THREESPINE STICKLEBACK SPECIES PAIR

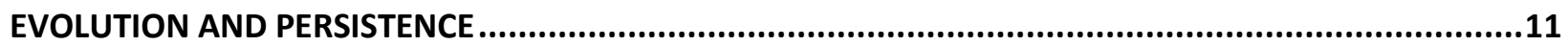

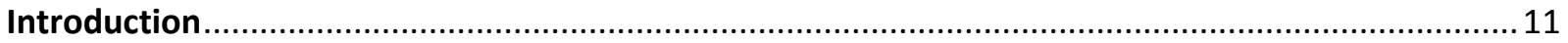

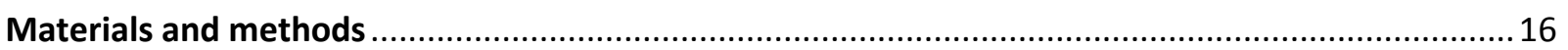

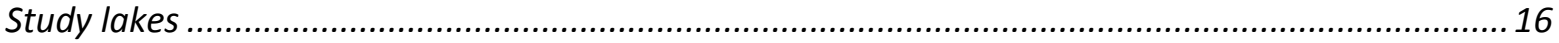

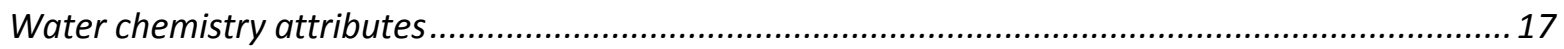

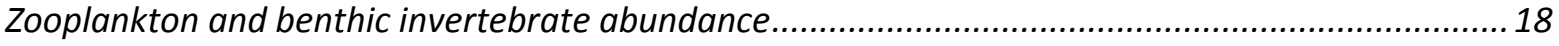

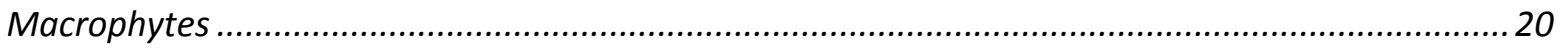

Bathymetry

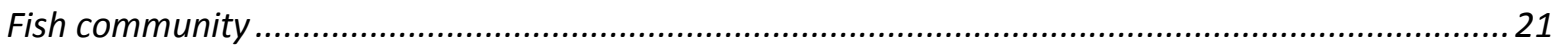

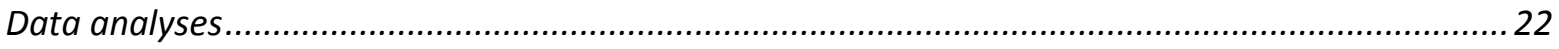

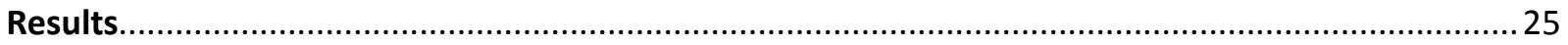

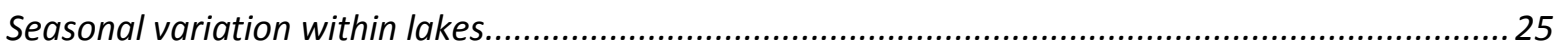

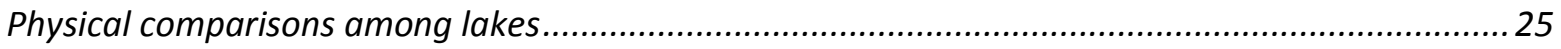

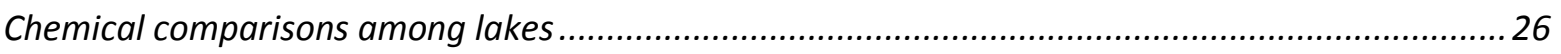

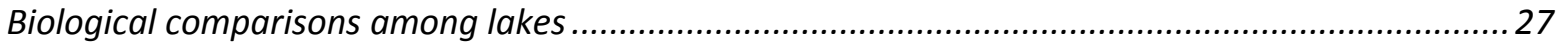

Comparison among lakes with all variables combined .................................................................28

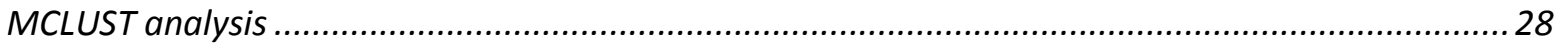

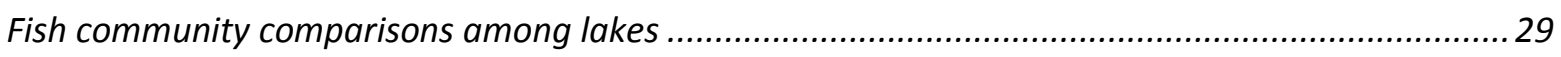

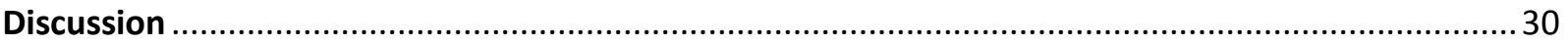

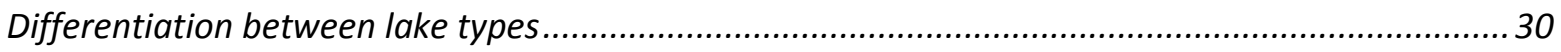

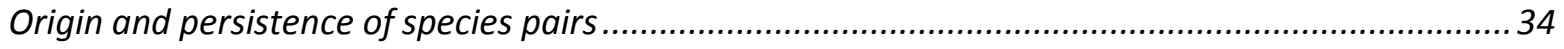

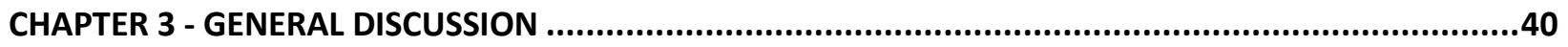

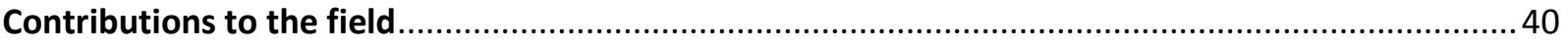

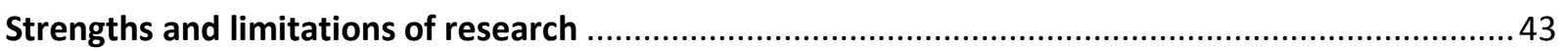


Future work

LITERATURE CITED .60

APPENDIX A - ENVIRONMENTAL VARIABLES USED IN STATISTICAL ANALYSES (PCA/DFA) ORGANIZED AS PHYSICAL, CHEMICAL, OR BIOLOGICAL FACTORS. .

APPENDIX B - SEASONAL RANGES OF CHEMICAL AND BIOLOGICAL VARIABLES FOR PAXTON AND CRANBY LAKES. 74

APPENDIX C - FACTOR LOADINGS FOR PCA OF PHYSICAL VARIABLES .75

APPENDIX D - FACTOR LOADINGS FOR PCA OF CHEMICAL VARIABLES... .76

APPENDIX E - FACTOR LOADINGS OF PCA OF BIOLOGICAL VARIABLES .77

APPENDIX F - FACTOR LOADINGS FOR PCA OF ALL VARIABLES COMBINED. .78 


\section{List of Tables}

Table 1. Species pair and non-species pair lakes sampled. B = smallmouth bass (Micropterus dolomeiui), $\mathrm{Ca}=$ brown bullhead catfish (Ameiurus nebulosus), $\mathrm{C}=$ coastal cutthroat trout (Oncorhynchus clarkii clarkii), Sc = prickly sculpin (Cottus asper), $\mathrm{S}=$ threespine stickleback (Gasterosteus aculeatus), and $\mathrm{R}=$ rainbow trout (Oncorhynchus mykiss). 46

Table 2. Underlying rock types of all species pair and non-species pair lakes. Rock type data were collected from British Columbia Ministry of Energy Mines and Petroleum Resources (2004). 


\section{List of Figures}

Figure 1. Hypothetical outcomes of two scenarios for threespine stickleback (Gasterosteus aculeatus) species pair evolution. A: supports the hypothesis of consistent environmental differences between species pair and non-species pair lakes, B: expected outcome under the null hypothesis. Open symbols represent species pair lakes; closed symbols represent non-species pair lakes

Figure 2. Map of study area. Species pair lakes are represented by rectangles; non-species pair lakes are represented by circles. $1=$ Balkwill Lake, $2=$ Priest Lake, $3=$ Emily Lake, $4=$ Paxton Lake, $5=$ Little Quarry Lake, 6 = Hadley Lake, 7 = Enos Lake, $8=$ Cranby Lake, $9=$ Ambrose Lake, $10=$ North Lake, 11 $=$ Brown Lake, $12=$ Chemainus Lake, $13=$ Stowell Lake, and $14=$ Weston Lake.

Figure 3. Bar plots of macrophyte coverage, chlorophyll a, coloured dissolved organic matter, and $\mathrm{pH}$ measured seasonally for Paxton and Cranby lakes. In the macrophyte plot Paxton Lake is represented by "P" and Cranby Lake is represented by "C." For the remaining plots Paxton Lake is represented by white bars and Cranby Lake by black bars.

Figure 4. Scatter plot of mean scores along PC1 and PC2 for the principal components analysis of physical variables. Principal component 1 and PC2 account for $82.6 \%$ of the total variation, 55.7\% and $26.9 \%$ respectively. Variables included were perimeter, surface area, relative littoral area, and maximum depth. Open squares are species pair lakes and filled circles are non-species pair lakes.

Figure 5. Bar plots of conductivity $(\mathrm{p}=0.052)$ and dissolved inorganic carbon $(\mathrm{p}=0.056)$ for all species pair (open bars) and non-species pair lakes (filled bars).

Figure 6. Bar plots of total dissolved solids $(\mathrm{p}=0.062)$ and alkalinity (total as $\left.\mathrm{CaCO}_{3} ; \mathrm{p}=0.077\right)$ for all species pair (open bars) and non-species pair lakes (filled bars).

Figure 7. Scatter plot of mean scores along PC1 and PC2 for the principal components analysis of chemical variables. Principal component 1 and PC2 account for $68.2 \%$ of the total variation, $43.5 \%$ and $24.7 \%$ respectively. Variables included were $\mathrm{pH}$, conductivity, turbidity, dissolved oxygen, temperature, water transparency, chlorophyll a, dissolved organic carbon, total organic carbon, coloured dissolved organic matter, dissolved inorganic carbon, total nitrogen, total phosphorous, alkalinity (total as $\mathrm{CaCO}_{3}$ ), and total dissolved solids. Open squares are species pair lakes and filled circles are non-species pair lakes.

Figure 8. Bar plot of total macrophyte abundance $(\mathrm{p}=0.70)$ for all species pair (open bars) and nonspecies pair lakes (filled bars).

Figure 9. Scatter plot of mean scores along PC1 and PC2 for the principal components analysis of biological variables. Principal component 1 and PC2 account for $81.5 \%$ of the total variation, $52.9 \%$ and $28.6 \%$ respectively. Variables included were zooplankton biomass, invertebrates in sediment biomass, 
invertebrates on rock biomass, and emergent, submergent, and total macrophyte abundance. Open squares are species pair lakes and filled circles are non-species pair lakes.

Figure 10. Scatter plot of mean scores along PC1 and PC2 for the principal components analysis of all physical, chemical, and biological variables combined. Principal component 1 and PC2 account for 56.1\% of the total variation, $35.5 \%$ and $20.5 \%$ respectively. Open squares are species pair lakes and filled circles are non-species pair lakes.

Figure 11. MCLUST analysis of species pair and non-species pair lakes along the principal component one and two axes. Each ellipse has equal variance. Weston, Stowell, Ambrose, Cranby, Enos, Hadley, and Balkwill lakes form one group. North, Brown, and Little Quarry lakes from a second group, Chemainus Lake forms a third group, Paxton Lake forms a fourth group, Priest Lake forms a fifth group, and Emily Lake forms a sixth group.

Figure 12. Cluster analysis (single linkage) on fish species composition in SP and NSP lakes using Jaccard's similarity index for presence-absence data. Variables included were threespine stickleback, coastal cutthroat trout, prickly sculpin, and rainbow trout. Species pair lakes are denoted by an '*' while non-species pair lakes are unmarked. 


\section{Acknowledgements}

I've had a lot of good times throughout the course of my Master's work and I would like to thank my supervisors Jordan Rosenfeld and Rick Taylor for giving me this opportunity. I appreciate all the guidance and encouragement you have given me and have learned a lot along the way. It was a pleasure to get to know you both.

I'd also like to extend a big thanks to all the people I shared a lab with: Damon Nowosad, J.S. Moore, Jon Mee, Monica Yau, Patricia Woodruff, Travis van Leeuwan, Les Harris, Patrick Tamkee, Gerrit Velema, Antoine Leduc, Matt Siegle, and Stefan Dick. I feel fortunate to know you all and I'm sure I'll remember you guys long after I forget what a stickleback is.

I also had help during my field work and for that I thank Patricio Salazar and Damon Nowosad. You guys can really paddle a canoe! And thank you to Gary Norris for collecting water samples at the majority of my study lakes. Thank you to Blake Matthews for sharing his zooplankton sampling and identification knowledge and to Craig Mount for sharing his knowledge of bathymetry and GIS.

I'd like to thank my parents Kamla Ormond and Randolph Ormond for all their encouragement and support throughout the years. And last but not least, thank you to the stickleback and your weird lifestyle. 


\section{Chapter 1 - General Introduction}

\section{Biological diversity and speciation}

Understanding the origins of biological diversity is a fundamental goal of ecology and evolution, but one of the most challenging because the slow pace of evolution usually makes direct observation of the process and outcomes difficult. There are, however, a small number of taxa, such as threespine stickleback (Gasterosteus aculeatus; Schluter and McPhail 1992) species pairs, lake whitefish species pairs (Coregonus clupeaformis; Bernatchez et al. 1999), East African cichlid species flocks (reviewed by Meyer 1993), and walking stick insects (Timema cristinae; Nosil et al. 2002), that are the products of very recent evolution, and these provide an invaluable window into the process of evolution and adaptation. Understanding the origins of species is equally fundamental to their conservation, since disruption of the adaptive landscape that may have generated such diversity can lead to extinction (Allendorf et al. 2001; Rhymer et al. 1996; Seehausen et al. 1997; Taylor et al. 2006).

Speciation can be initiated when a single lineage or population becomes separated into two or more daughter lineages either by a physical separation event (allopatric speciation) or through disruptive selection (sympatric speciation; Coyne and Orr 2004). Such isolation is often associated with expansion into new habitats and the development of different feeding strategies and behaviours which can lead to different morphology and physiology. Over time these now different populations can become increasingly segregated due to natural selection and may eventually become reproductively isolated from each other and constitute new biological species (Dieckmann and Doebeli 1999). In sympatry, disruptive selection is difficult to measure in 
nature, but is often inferred from observations of resource polymorphisms or incipient sympatric species. These occurrences are particularly valuable in understanding the evolution of species as they seem to represent an early stage of speciation (Schluter 2000).

One of the most commonly accepted pathways of speciation is allopatric speciation. Darwin's finches (Geospiza spp.) are a famous example of how dispersal and physical separation can promote the formation of new species. One species of finch from Central or South America is thought to have colonized Cocos Island and 13 different Galapagos Islands and on each island this ancestral species diversified to exploit different resources such as different sized seeds, insects, or nectar (Grant and Grant 2002).

On the opposite end of the spectrum of the geography of speciation is sympatric speciation. In sympatric speciation, a single species can genetically diverge into two or more species without being physically separated. Species that are thought to have arisen sympatrically are normally segregated ecologically by their habitat and/or resource use and overlap in their ranges for some portion of their life cycle (reviewed by Johannesson 2001). Because of this overlap, hybrids can occur between sympatric species but are generally thought to be less fit than the parental species (e.g. Foote and Larkin 1988; McPhail 1994; Gow et al. 2006, but see Arnold 1997). Sympatric speciation has been suggested to occur in a variety of taxa such as birds, fish, insects, and crustaceans (reviewed by Bush 1994). One example involves the incipient species of marine snail Littorina saxatilis found in Spain that occur sympatrically as two morphs. One morph with a smooth unbanded shell lives in the low intertidal zone amongst blue mussels (Mytilus galloprovincialis) while a second morph has a ridged and banded shell and lives 10-20 m higher 
up the shore amongst barnacles (Chthamalus stellatus). These two morphs overlap in the mid intertidal zone and hybridize to some extent although intermating is not random possibly due to female sexual selection (Johannesson 1995).

\section{Habitat heterogeneity, speciation, and extinction}

One of the key components of allopatric and sympatric modes of speciation is habitat heterogeneity and the role of natural selection in promoting adaptation to alternative environments and the subsequent effects of such adaptive radiation on reproductive isolation. For instance, in allopatric speciation, the populations on either side of a dispersal barrier may undergo divergent natural selection such that when they come into secondary contact pre-or postmating barriers have evolved that result in reproductive isolation. Similarly, in sympatric speciation, the presence of alternative, but limited, resources in the same environment may promote disruptive selection within a polymorphic population such that reproductive isolation evolves either directly via hybrid disadvantage or indirectly via pleiotropy (Rice 1987; reviewed by Pfennig and McGee 2010). In both modes of speciation, the idea that environmental heterogeneity was an important aspect of the environment in the initial divergence suggests, at least for recently-derived species, that maintenance of such environmental heterogeneity is essential to the persistence of sympatric species. In fact, loss of habitat and heterogeneity is a leading cause of extinctions and extirpations of many taxa (Dextrase and Mandrak 2006, Venter et al. 2006). Loss of heterogeneity or quality can result in increasing interactions between species that can elevate hybridization between species and/or alter the relative fitness of hybrids and potentially cause extinction via the collapse of species into hybrid swarms (Seehausen 2006; Hendry et al. 2006; Taylor et al. 2006). It is, therefore, important to understand the effects that 
habitat structure, quality, and heterogeneity have on the persistence of species as a general goal in biodiversity conservation.

\section{Interspecific competition and speciation}

In addition to habitat heterogeneity, interspecific competition also appears to play an important role in adaptive radiations (Schluter 2000). Intense interspecific competition can limit the expansion of a diversifying species by limiting food resources and habitat availability (i.e. no open niches available) and causing the less competitive species to either use alternative resources or to disappear through competitive exclusion (Grant 1994; Robinson and Wilson 1994; Losos 2000). The effects of interspecific competition have been documented by Harrington et al. (2009) in the case of the introduced American mink (Neovison vison) population in England where two native mustelids (competitors) were extirpated while the introduced American mink was able to establish a viable population. Without competitor species the American mink was diurnal and attained a large body size but after reintroduction of the two native mustelids the American mink attained a reduced body size and became nocturnal. Similarly, Belant et al. (2006) showed that in years where salmon (Oncorhynchus spp.) returns are low black bears (Ursus arctos) do not exploit a shared salmon prey resource most likely due to competition with the much larger brown bear (Ursus americanus). These examples show that intense competition can affect the behaviour and resource use of similar but weaker competitor species, either through interference (e.g. territoriality) or exploitative competition (e.g. where a more efficient competitor reduces resource abundance below the threshold required for persistence of the less efficient species). This pattern has also been seen in several lakes in North America containing lake whitefish (Coregonus clupeaformis), a benthic invertebrate predator, and lake cisco 
(Coregonus artedii), a specialized zooplanktivore. In lakes where these species coexist the lake whitefish occurs in only one form, benthic, however, in several lakes where lake cisco is absent the lake whitefish has diversified into two morphs, one specializing on benthos and one specializing on zooplankton. It, therefore, appears that a lack of interspecific competition opens up available resources thus promoting the divergence of a single species into new habitats (Lindsey 1981; Lu and Bernatchez 1999; Schluter 2000).

Intense intraspecific competition may also be a promoter of diversification within a species (Smith and Skulason 1996) as the competition for a limiting resource provides an impetus for range expansion. Hindar and Jonsson (1982) showed this in a study comparing the habitat and resource segregation between two Arctic char (Salvelinus alpinus) morphs in one lake. They found that the two morphs were adapted to different niches in the summer (benthic and limnetic), but that segregation broke down when resource abundance was high indicating that habitat segregation was due to intraspecific competition for resources and leading Hindar and Jonsson (1982) to conclude that the number of Arctic char morphs is dependent on the number of available niches in the summer when resources are limited.

The adaptive landscape (suite of biotic and abiotic conditions a species must adapt to) for lakedwelling fishes probably emerges, at least in part, from the interaction between the physical attributes of lakes and intra- and inter-specific competition. Lakes represent a heterogeneous environment, typically consisting of an open water or pelagic zone and a littoral benthic zone, but other diverse habitats may include beaches and stream mouths. These regions represent very different types of habitat with regards to both habitat structure and available resources. The 
pelagic zone begins at the edge of the littoral zone and encompasses all open waters within the photic zone (Wetzel 2001). As the pelagic zone does not have pronounced physical or biotic habitat structure it has relatively low functional diversity with the primary resource for fish being zooplankton. By contrast, the littoral zone includes the area from shoreline to the lowest depths of rooted macrophytes (Wetzel 2001). The littoral zone has both abiotic (rocks, woody debris) and biotic (macrophytes) habitat structure and normally has higher species diversity than the pelagic zone with the primary resource being macroinvertebrates, which are functionally diverse and often larger than plankton. Differences in lake habitat and prey resources are also linked to differences in morphology (body size, gill raker number etc.), behaviour (swimming and position in water column), and physiology (growth) of fishes (Schluter and McPhail 1993; Bernatchez et al. 1999; Rogers and Bernatchez 2005) all of which appear to be specialized for the habitat and its resource spectrum in which the organism lives. The number of competitor species can vary from lake to lake and can be another aspect of the environment that can influence phenotypic specializations in fishes (Lindsey 1981; Hindar and Jonsson 1982; Vamosi 2003).

\section{Species pairs of north temperate fishes}

Repeated glaciations in north temperate regions has resulted in a depauperate fish fauna, and there are many cases of sympatric species pairs which normally occur in limnetic-benthic forms (Robinson and Wilson 1994; Smith and Skulason 1996; Taylor 1999). These pairs are known to occur in, but are not exclusive to, the families Salmonidae (Foote and Larkin 1988; Bernatchez et al. 1999), Centrachidae (Robinson et al. 2000), Osmeridae (Taylor and Bentzen 1993), and Gasterosteidae (Larson 1976; Schluter and McPhail 1992). These species pairs occur in lakes with a heterogeneous environment and depauperate fish communities providing open niches and 
reduced competition and predation. These heterogeneous environments are associated with differences in temperature, substrate, depth, etc. that create divergence in the type of prey resources found in different regions of the lake allowing for adaptations to various forms of food (Hindar and Jonsson 1982; Taylor 1999). A particularly well-studied example of this phenomenon is the sympatric pairs of threespine sticklebacks (Gasterosteus aculeatus) that occur in several lakes on four islands in the central Strait of Georgia region of southwestern British Columbia (McPhail 1994; Gow et al. 2008). One form, the benthic, is deep bodied with few, short gill rakers and lives in the littoral zone feeding on benthic macroinvertebrates and the other form, the limnetic, is pelagic, slim bodied, has numerous long gill rakers, and feeds on zooplankton (Larson 1976; Schluter and McPhail 1992).

Given that the two stickleback species exploit distinct reproductive and trophic environments within the same lake and that this habitat heterogeneity has been suggested to be critical to the origin and persistence of the species pairs, disruptions to these habitats could compromise their existence (Rosenfeld and Hatfield 2006; National Recovery Team for Stickleback Species Pairs 2007; Hatfield 2009). A much studied example of this is the stickleback species pair in Enos Lake, British Columbia. At one time, this lake contained a sympatric pair of benthic-limnetic threespine stickleback which has now collapsed into a hybrid swarm (McPhail 1984; Taylor et al. 2006). One of the leading hypotheses for this hybridization is habitat alteration possibly caused by the introduced American signal crayfish (Pacifastacus leniusculus) which occurred at about the same time that the stickleback hybrids started to become more common in the lake (Kraak et al. 2001; Taylor et al. 2006). The crayfish may have altered the physical habitat (e.g., water clarity, macrophyte distribution and abundance) to such an extent that pre-zygotic (mating 
behaviour) or post-zygotic (relative fitness of hybrids) barriers to interbreeding between benthics and limnetics have degraded and promoted the formation of a hybrid swarm (Taylor et al. 2006; Behm et al. 2010). In another example, Landry et al. (2007), studied lake whitefish species pairs and concluded that there were consistent differences in the abiotic and biotic environments of lakes that contained species pairs exhibiting a high vs. low level of morphological differentiation. These differences were such that reduced habitat and prey availability occurred in lakes with highly diverged morphs which led the authors to suggest that these conditions increased intraspecific competition for resources and promoted the evolution of populations specializing on alternative resources. These examples suggest that there are certain habitat features of lakes that are critical to the persistence of divergent populations and that the identification of these features are central to any rational plan to conserve such populations.

\section{Conservation of species pairs}

Canada's Species at Risk Act (SARA) is legislation set in place to prevent the loss of and promote the recovery of species that are listed as endangered, threatened, or of special concern in Canada (Species at Risk Act 2002). A recovery strategy for all listed species is developed under SARA, which includes a definition of critical habitat for the listed species. Under SARA critical habitat is defined as "habitat that is necessary for the survival or recovery of a listed wildlife species and that is identified as the species' critical habitat in the recovery strategy or in an action plan for the species" (Species at Risk Act 2002). Given that threespine stickleback species pairs are extremely rare, known to occur in only five lakes in three watersheds, they are listed as endangered and are protected under SARA. As such, the critical habitat of these species pairs must be identified and my study set out to make a contribution to this need. Critical habitat 
for the stickleback species pairs will include all environmental factors that are needed to ensure that viable populations of both benthic and limnetic stickleback persist, including those factors that are important in maintaining reproductive barriers between benthics and limnetics (Rosenfeld and Hatfield 2006; National Recovery Team for Stickleback Species Pairs 2007; Hatfield 2009). This could include attributes such as water quality, available resources, and types of habitat available. Currently the specific environmental features important for species pair persistence are largely unknown and as such the entire lake may be critical habitat or it may be a subset of environmental features that are critical to the species. Through studies such as this one, critical habitat can be identified thereby leading management and conservation efforts toward more specific habitat protection measures.

\section{Thesis objectives}

The main goal of my study was to determine if there are environmental factors (biotic or abiotic) that are unique to stickleback species pair lakes that have contributed to the divergence and persistence of separate limnetic and benthic species in sympatry. Conceptually, the null model is that the occurrence of stickleback species pairs is not dependent on any particular constellation of environmental factors but instead is due entirely to historical events that have resulted in a very limited opportunity for the evolution of sympatric species pairs, e.g., random colonization of selective lakes by previously divergent populations, biased extinctions of one member of a pair, or random demographic conditions (e.g., population bottlenecks) that have constrained divergence in most lakes. The alternative hypothesis is that limnetic and benthic species pairs have evolved due to specific abiotic and biotic environmental factors shared amongst lakes with species pairs. To test this hypothesis I compared physical, chemical, and biological attributes of 
species pair lakes with those of non-species pair lakes and predicted that species pair lakes would show a clear difference in habitat structure and resource abundance when compared to nonspecies pair lakes. 


\section{Chapter 2 - Environmental Determinants of Threespine Stickleback Species Pair Evolution and Persistence}

\section{Introduction}

The evolution of closely related pairs of trophically differentiated species of freshwater fishes is a repeated occurrence in north temperate lakes that is usually attributed to ecological radiation within depauperate fish faunas (Robinson and Wilson 1994; Taylor 1999). Recently evolved taxa are of great value to understanding processes of evolution, and are often endemics with restricted distributions and, therefore, of significant conservation concern (Schluter 2000). Understanding the processes that lead to species differentiation is a central goal of evolutionary biology, but may also provide essential information for species management. From a conservation standpoint, the limnological conditions that are required for species differentiation may also be essential for continued species persistence, and alteration of limnological attributes has been associated with the irreversible collapse of recently evolved species into hybrid swarms (Todd and Stedman 1989; Seehausen et al. 1997; Taylor et al. 2006).

One possible pre-condition for the evolution of trophically differentiated lacustrine species is their occurrence in adaptive landscapes with unusual limnological attributes (e.g. an unusual type of habitat(s) with a unique range of water chemistry or trophic conditions). Alternatively, there may be nothing intrinsically unique about the characteristics of the waterbodies where species pairs evolved, and their presence in particular water bodies may be due solely to random colonization events or landscape filters that limited colonization and fish faunal diversity (Poff 
1997; Jackson et al. 2001). These contrasting scenarios have different conservation implications, with the first suggesting that maintaining unique limnological attributes (e.g. nutrients, habitat, or water quality) is paramount for species persistence, whereas the second suggests that other concerns such as preventing invasions by exotic taxa are higher priorities. A lack of unique characteristics for lakes with species pairs would also suggest that their existence in some lakes and not others is a result of chance historical events such as differences in opportunities for multiple invasions (McPhail 1993).

Several studies have considered the effects of environmental factors on population divergence and concluded that the environment can and does affect how species change and adapt. Well known examples include the cichlids of East African lakes (Seehausen et al 2008), Darwin's finches (Grant and Grant 2002), and Anolis lizards from the Caribbean (Losos et al 1997). Recently, it was suggested that limnological attributes of lakes influence the evolution of lake whitefish (Coregonus clupeaformis) species pairs, which show a higher degree of differentiation between limnetic and benthic ecotypes in lakes with reduced habitat and prey availability thereby increasing intraspecific competition for resources (Landry et al 2007).

Sympatric limnetic and benthic threespine stickleback (Gasterosteus aculeatus) species pairs are a well-studied example of recent speciation that are of significant conservation concern (globally Endangered) and an ideal system for exploring these hypotheses and their conservation implications (McPhail 1994; Schluter 2000). Sympatric pairs of threespine stickleback are known to occur in seven lakes in five watersheds in the Strait of Georgia, British Columbia (McPhail 1984; McPhail 1992; Schluter and McPhail 1992; Gow et. al. 2008). In each of these 
lakes stickleback occur in benthic and limnetic forms (Larson 1976) and are adapted to their specific microhabitat. Benthic sticklebacks have robust bodies with few, short gill rakers and feed on macroinvertebrates in the littoral zone while limnetic stickleback have a streamlined body form with many, long gill rakers and feed on zooplankton in the limnetic or pelagic zone (Larson 1976; Schluter and McPhail 1992).

The origin of these species is unclear. Currently the most accepted hypothesis is the double invasion scenario, which postulates two separate invasions of a marine stickleback ancestor into each of these five watersheds (McPhail 1993; Schluter and McPhail 1992). The exact timing of postglacial invasions is still uncertain (Hutchinson et al. 2004); however, Taylor and McPhail (2000) concluded that limnetic sticklebacks are genetically more closely related to present day marine stickleback than are benthic sticklebacks thereby supporting double invasion and suggesting that the first wave of invaders became the benthic form and the second wave of invaders the limnetic form.

Although a double invasion scenario may explain the existence of sympatric species pairs, many other lakes in the region that were presumably subject to more than one marine transgression currently only contain a single species of stickleback (non-species pair lakes). The fact that only seven lakes out of the multitude of lakes in the region contain stickleback species pairs suggests that these lakes are physically or biologically unique in some way that promoted the evolution of sympatric species pairs. Vamosi (2003) compared a limited number of physical attributes of species pair and non-species pairs lakes and while finding no significant differences between these lake types he found that they differed in their fish communities. Stickleback species pair 
lakes were found to contain only stickleback and coastal cutthroat trout and most non-species pair lakes contained both of these fishes in addition to other fish species; although some nonspecies pair lakes also contain only stickleback and coastal cutthroat trout. Finally, Vamosi's (2003) study did not include the Little Quarry Lake species pair because it was not yet discovered. In this study, I include all known species pair lakes and test the hypothesis that limnetic and benthic stickleback species pairs have evolved due to some single or combination of unique environmental factors that are shared amongst species pair lakes, but are absent in nonspecies pair lakes. To test this hypothesis, physical, chemical, and biological variables were compared between lakes with and without species pairs. If species pair lakes group separately from all other lakes (Figure 1), this will support the inference that a unique combination of environmental variables in these lakes were important determinants of stickleback species pair divergence. No difference in environmental attributes between species pair and non-species pair lakes supports the alternative hypotheses that i) evolution of species pairs is a consequence of random colonization processes that allowed a double invasion on a random subset of lakes, or ii) differences in fish community structure prevent speciation, (e.g. Vamosi 2003 and Figure 1) rather than unique biophysical properties of species pairs lakes.

As benthic and limnetic sticklebacks show clear differences in habitat selection, any lake that species pairs occur in will be required to meet the habitat needs of both species (i.e. contain both littoral and pelagic zones). A lake with no littoral zone would probably not allow for the evolution and persistence of benthic sticklebacks and a lake with no open water zone would probably not permit the persistence of limnetic sticklebacks. In addition, the relative abundance of macrophytes may be important to both species as they provide nesting material (McPhail 
1994) and cover for benthic stickleback and their prey (macroinvertebrates), while they reduce the amount of open water available thereby reducing habitat for both limnetic stickleback and their prey (zooplankton). As such, I expected to see a clear difference in habitat types between species pair and non-species pair lakes as measured by the amount of relative littoral area and macrophyte abundance.

Because benthic and limnetic sticklebacks feed on different resources, macroinvertebrates and zooplankton respectively, lakes containing species pairs probably require sufficient resources of each food type to support populations of both species. Consequently, I expected to see a difference in available resources between species pair and non-species pair lakes due to differences in productivity or fish species composition of the lakes with species pair lakes having a wider range of resource availability or higher productivity than non-species pair lakes.

Both species pair and non-species pair lakes contain stickleback and coastal cutthroat trout (Oncorhynchus clarkii clarkii); however, several non-species pair lakes also contain prickly sculpin (Cottus asper) or rainbow trout (Oncorhynchus mykiss). These additional fish species may act as competitors and/or predators of stickleback and therefore deplete the amount of resources available and prevent range expansion, reducing the scope for resource specialization. For example, the prickly sculpin is a benthic fish that feeds mainly on macroinvertebrates (Brown et al. 1995) and may be a better competitor for benthic resources than stickleback, potentially reducing benthic invertebrate abundance below a threshold required for stickleback divergence. Rainbow trout are also known to feed on benthic invertebrates as adults (Nilsson and Northcote 1981) and on zooplankton as juveniles (Beauchamp 1990), thus rainbow trout 
may be competitors of both benthic and limnetic stickleback. In addition, both prickly sculpin (Pressley 1981) and adult rainbow trout are predators of stickleback (Reimchen 1994).

\section{Materials and methods}

\section{Study lakes}

Fourteen lakes in southwestern British Columbia containing threespine stickleback were sampled during this study (Table 1, Figure 2). Seven of the sampled lakes contain, or have historically contained, threespine stickleback species pairs (species pair lakes, SP) and the other seven lakes contain a solitary population of threespine stickleback (non-species pair lakes, NSP; Table 1) in addition to other fish species. All known SP lakes were sampled; NSP lakes sampled were between $45-100 \mathrm{~m}$ in elevation and $\leq 5000 \mathrm{~m}$ distant from the sea because this is the range of elevations and distances encompassed by SP lakes (and therefore should have the same historical probability of being colonized repeatedly by a marine ancestor as the SP lakes). Elevation and distance to sea were chosen following McPhail (1993) and Vamosi (2003) with an estimated maximum $10 \%$ error in measuring these parameters. It has been found that all SP lakes, with the exception of Little Quarry Lake that currently contains only stickleback but may, at one time, have contained coastal cutthroat trout that were later extirpated due to the creation of a dam that may have blocked access to spawning grounds, contain only one other species of fish, coastal cutthroat trout. Thus, it would have been ideal to sample NSP lakes that contain only stickleback and coastal cutthroat trout, however, this was not possible because of the limited number of lakes with this specific simplified fish community. Therefore, the group of NSP lakes sampled contained the following fish assemblages: 1) Cranby Lake - stickleback + coastal cutthroat trout, 
2) Ambrose, Brown, and North Lake - stickleback + coastal cutthroat trout + prickly sculpin, 3)

Stowell and Weston Lake - stickleback + coastal cutthroat trout + rainbow trout and 4)

Chemainus Lake - stickleback + coastal cutthroat + rainbow + (introduced, non-native) smallmouth bass (Micropterus dolomieu; Table 1).

All lakes were sampled for water chemistry, trophic resources, and macrophyte abundance once between July 6 and August 28, 2008 and again at Paxton and Cranby lakes between November 29 and December 1, 2008 and April 20-21, 2009. Bathymetric surveys were completed at each lake between July 6 and August 28, 2008. Seasonal sampling was completed on one SP lake (Paxton Lake) and one NSP lake (Cranby Lake) as representatives of each lake group. These lakes were chosen because they have similar fish communities (Table 1) and are geographically close to each other (Table 1, Figure 2), presumably making them the most alike among SP and NSP lakes. By sampling Paxton and Cranby Lakes over three different seasons I was able to look for seasonal differences between lake groups.

\section{Water chemistry attributes}

I sampled water chemistry parameters that were related to nutrient and trophic status including: $\mathrm{pH}$, conductivity, turbidity, dissolved oxygen, temperature, water transparency, chlorophyll a, dissolved organic carbon (DOC), total organic carbon (TOC), coloured dissolved organic matter (CDOM), dissolved inorganic carbon (DIC), total nitrogen (TN), total phosphorous (TP),

alkalinity (total as $\mathrm{CaCO}_{3}$ ), total suspended solids (TSS), and total dissolved solids (TDS). 
Turbidity samples were taken at a depth of $0.5 \mathrm{~m}$ and measured using a Lamotte 2020e turbidity meter. Surface readings of $\mathrm{pH}$ and conductivity were measured using a YSI WTW340i meter. Dissolved oxygen (DO) and temperature were measured using a YSI model 58 oxygen meter every $0.5 \mathrm{~m}$ of depth to create DO and temperature profiles of each lake. Water transparency was measured using a Li-Cor Model LI-250 light meter at $0.12 \mathrm{~m}, 0.5 \mathrm{~m}, 1.5 \mathrm{~m}, 2.5 \mathrm{~m}$, and 3.5 $\mathrm{m}$ and light extinction coefficient $(\mathrm{k})$ values were calculated. For all other variables, water samples were taken within $100 \mathrm{~m}$ of the geographic centre of each lake at a depth of $0.5 \mathrm{~m}$ and analysed by Maxxam Analytics (Burnaby, BC).

\section{Zooplankton and benthic invertebrate abundance}

At each lake, three vertical zooplankton tows were collected using a $30 \mathrm{~cm}$ wide Wisconsin plankton net with an $80 \mu \mathrm{m}$ mesh size at the deepest area of the lake. Depth of the tows varied with each lake to ensure the tows reached through the thermocline so as to maximize the collection of vertically migrating zooplankton (Wetzel 2001). Samples were filtered through a $250 \mu \mathrm{m}$ mesh and preserved in 5\% formalin. Volume of water filtered for each tow was

calculated using the formula $\mathrm{V}=\pi \mathrm{r}^{2} \mathrm{~h}$, where $\mathrm{r}$ is the radius of the plankton net mouth and $\mathrm{h}$ is the depth of the vertical tow. Sampling methodology followed Tonolli (1971).

Benthic invertebrates were collected from both sediment and rock substrates and are not meant to characterize each lake completely but instead are meant to determine relative differences between lakes. Three sediment and five rock samples were taken at each lake. More rock samples than sediment samples were taken because the rock substrate appeared to be more variable than the sediment substrate. Sediment sampling stations were chosen systematically to 
include separate areas of each lake; rock sampling stations were chosen first by locating the rocky zones within each lake and then randomly choosing the rocks to be sampled. Sediment samples were collected by carefully scooping sediment from a known area $\left(0.0075 \mathrm{~m}^{2}\right)$ into a $250 \mu \mathrm{m}$ mesh net attached to the end of a pole and held against the lake bottom, filtering the sediment through a $250 \mu \mathrm{m}$ mesh, and preserving the sediment in $5 \%$ formalin. Rocks were collected by carefully placing them into a $250 \mu \mathrm{m}$ mesh net held next to the substrate before lifting the net out of the water, and scrubbing the rock with a brush to wash off all invertebrates. Invertebrates were rinsed from the rock and net and were preserved in 5\% formalin. To express invertebrate abundance as a density, the surface area $\left(\mathrm{m}^{2}\right)$ of each rock was calculated based on rock length and width.

In the lab, zooplankton samples were divided into quarters or eighths depending on zooplankton density using a splitter so that each counted sample had not more than 2,000 individuals. Accuracy of the split samples was assessed by splitting a sample and counting each subsample. The lengths of 30 individuals of each taxon in the subsamples were measured using a digitizing system (magnification 10X; Roff and Hopcroft 1986) and all individuals in the subsamples were counted. Cladocerans were identified to family or genus, copepods were identified as order Calanoida, order Cyclopoida, or as copepod nauplia. Chaoborus spp. were identified to family and mites were identified as subclass Acarina. Biomass for zooplankton were determined using length-weight regressions (Weight $=\mathrm{a}^{*}$ Length $^{\mathrm{b}}$; where $\mathrm{a}$ is the intercept and $\mathrm{b}$ is the slope) from Culver et al. (1985) and Yan and Mackie (1987). Biomasses were not corrected for plankton net efficiency as doing so would represent only a change in magnitude and would not affect the results. 
Invertebrate samples from rocks were counted whole and not large enough to justify subsampling, whereas larger invertebrate samples from sediment were divided using a splitter. Large samples containing $250 \mathrm{ml}$ of sediment were divided into quarters and samples of $125 \mathrm{ml}$ of sediment were divided in half. Accuracy of splitting was determined using the same procedure as for zooplankton. Invertebrates were identified to subclass, order, family, or genus. Length of each invertebrate was measured using the same digitizing system used for zooplankton. Biomasses for benthic invertebrates were calculated using length-weight regressions as published by Benke et al. (1999), Sample et al. (1993), and Smock (1980).

\section{Macrophytes}

Emergent and submergent macrophyte coverage was surveyed systematically over entire lakes and calculated at each lake as a percent of total lake surface area. Using a canoe, I travelled along the perimeter of each lake and the area of macrophyte beds were either measured using a range finder or by eye after calibrating visual estimates against rangefinder readings.

\section{Bathymetry}

The littoral area is often defined as either the portion of a lake that is less than $6 \mathrm{~m}$ deep or the area that stretches from the shoreline out to where sufficient light for plant growth reaches the lake bottom (e.g. British Columbia Ministry of Environment Ecosystems Branch 2009; Wetzel 2001). For this study, I chose to define the littoral area as the portion of the lake that is less than $3 \mathrm{~m}$ in depth. My reasoning for this was the majority of macrophytes are within the $3 \mathrm{~m}$ depth contour and also that stickleback (both benthic and limnetic) typically breed at depths of less 
than $2 \mathrm{~m}$ (McPhail 1994; Hatfield and Schluter 1996). Therefore, the area of depth less than $3 \mathrm{~m}$ will contain the most habitat structure for benthic and juvenile sticklebacks and is most important for stickleback reproduction.

To determine relative littoral area (RLA), multiple transects of each lake were made and bathymetric data were collected using a Lowrance LMS-525C DF GPS Fishfinder. Relative littoral area was extracted from the bathymetric data by uploading the UTM coordinates and corresponding depths onto georeferenced maps in ArcGIS. Contours were then made using the 3D Analyst tool and the relative littoral area (depth $<3 \mathrm{~m}$ ) for each lake was calculated. Maximum depth was also extracted from bathymetric data. Measures of perimeter and surface area were extracted from georeferenced maps in ArcGIS.

\section{Fish community}

The fish communities of each lake were determined from Fish Wizard (http://www.fishwizard.com; an online database that contains information on fish distributions in British Columbia) and Vamosi (2003). For analysis of the fish community exotic fish species (e.g. smallmouth bass; present in no SP lakes and one NSP lake, brown bullhead catfish, Ameiurus nebulosus; present in one extirpated SP lake and no NSP lakes) were not included and therefore only stickleback, coastal cutthroat trout, rainbow trout, and prickly sculpin were used, since the intention was to determine whether there was a distinct historical fish community associated with the evolution of species pairs. Rainbow trout have been stocked in both Weston and Chemainus Lakes (NSP lakes; British Columbia Ministry of Environment Fisheries Information Data Queries 2010) and, therefore, may not be native to those lakes; however, the 
fish community previous to this stocking is unknown and as rainbow trout are native to the region (Scott and Crossman 1973) it is possible that they are native to these lakes. As such, I consider rainbow trout to be native fishes in this study.

\section{Data analyses}

All statistical analyses were completed on data collected in summer 2008. Seasonal data was not included in any statistical analyses. All physical, chemical, and macrophyte data are from single measurements whereas zooplankton and benthic invertebrate biomasses represent averages. Student's $t$-tests were used on each variable to test for statistical differences between the mean values for each lake group (SP vs. NSP) using the spreadsheet-based general statistics program PAST (Hammer et al. 2001). When tests for homogeneity of variances failed the Welch test was used in PAST.

Principal components analysis (PCA) was used to see if there were broad differences between SP and NSP lakes. Principal components analysis is a common multivariate method that takes the original correlated variables and finds uncorrelated combinations of these variables called principal components. The majority of variation in the data is described by the first few principal components, thereby reducing the number of variables needed to describe the data while retaining most information. For this analysis, the correlation matrix was used as the variables were measured on different scales (Manly 2005). The Jolliffe stopping rule was used to retain all eigenvalues (PC axes) greater than 0.70. Although the Kaiser-Gutman method, which retains eigenvalues $>1.0$, is one of the most common methods I chose the Jolliffe rule as it retains more principal components and therefore more information about the objects (Jackson 
1993). I conducted $t$-tests of the retained PC scores from physical, chemical, biological, and combined PCAs between SP and NSP lakes.

Following PCA, discrimnant function analysis (DFA) was used to differentiate between SP and NSP lakes if the Hotelling's multivariate $\mathrm{T}^{2}$ test indicated a significant difference in PC scores existed between SP and NSP lakes (Manly 2005). The PCAs and DFAs both were performed on the retained PC scores using PAST for all variables combined and on physical, chemical, and biological variables separately (Appendix A). The discriminant analyses employed the "leaveone-out" procedure (leaving out whole lakes) to determine the accuracy of correct allocations of lakes into groups by the analysis (Manly 2005). The physical PCA/DFA included four variables, chemical PCA/DFA included 19 variables, biological PCA/DFA included six variables, and the combined PCA/DFA included 29 variables (Appendix A).

Invertebrate biomass on rock and sediment could not be collected for several lakes because one or the other substrate was absent. These missing observations (For rock, $\mathrm{n}=5$; for sediment, $\mathrm{n}=$ 2) were predicted by linear regression of total nitrogen on invertebrate biomass (For rock, $y=$ 4646.2x -189.95 ; for sediment, $\mathrm{y}=12109 \mathrm{x}+680.36)$. I had the a priori expectation that invertebrate biomass would increase as total nitrogen increased because nitrogen contributes to primary productivity (Wetzel 2001) thereby increasing food resources for benthic invertebrates (e.g. Blumenshine et al. 1997) and therefore a one-tailed test for significance of these relationships was used. Linear regressions for invertebrate biomass on rock and sediment had pvalues of 0.05 and 0.045 respectively (one-tailed $t$-test). 
The statistical program MCLUST (Fraley and Raftery 2003) was used in R (R Development Core Team 2008) to empirically and objectively determine the number of groups formed by the lakes for the combined data set only. This is a model-based clustering analysis where there is no a priori designation of the number of groups of lakes. Several models, where each model consists of a different number of groups of lakes from 1 through to the number of individual lakes $(\mathrm{N}=14)$, are compared at the same time by MCLUST which then identifies the best model for the data based on the Bayesian Information Criterion (BIC). This best model has the highest BIC and an associated number of groups of lakes as well as characteristic dispersion of lakes within groups. Following the hypothesis that SP and NSP lakes will differ in their suite of environmental parameters, I predicted that the best model selected by MCLUST would be two: SP and NSP lakes. Only PC axes retained after using the Jolliffe stopping rule were used in the MCLUST analysis (PC axes 1-8).

The distribution of fish species across SP and NSP lakes was analysed using a single linkage (nearest neighbour) hierarchic cluster analysis using Jaccard's similarity index, which is commonly used for presence-absence data (Jackson et al. 1989; Manly 2005). Jaccard's index does not include negative matches and, therefore if a species is mutually absent from several sites, this absence does not contribute to similarity between the sites (Cairns and Kaesler 1969). This index is appropriate for my study because some fish species only occur in a few of my study lakes (e.g., prickly sculpin occur in only three of 14 lakes) and by using Jaccard's index lakes will cluster by positive matches alone. Jaccard's index ranges from zero (no similarity) to one (complete similarity). 


\section{Results}

\section{Seasonal variation within lakes}

Although no statistics were conducted on the seasonal data, bar plots suggested a few differences between Paxton and Cranby lakes across seasons (Figure 3, Appendix B). One of the main differences was in macrophyte abundance. The macrophytes in Paxton Lake remained relatively constant across seasons (between 27.2 - 30.5\%) while in Cranby Lake macrophyte abundance decreased from summer 2008 (18.3\%) to fall 2008 (10.3\%) and spring 2009 (0.6\%). Chlorophyll a fluctuated in Paxton from $0.8 \mu \mathrm{g}$ to $13.8 \mu \mathrm{g}$ to $7.6 \mu \mathrm{g}$ in summer, fall, and spring respectively, while chlorophyll a in Cranby Lake was relatively constant across seasons. Coloured dissolved organic matter and $\mathrm{pH}$ showed little variation between lakes or across seasons (Figure 3, Appendix B).

\section{Physical comparisons among lakes}

Principal component 1 and PC2 accounted for $55.7 \%$ and $26.9 \%$ respectively of the total variance from the PCA on only physical variables. Perimeter (-0.6167), surface area (-0.577), and maximum depth (-0.4867) showed strong negative correlations with PC1, which contrasted large, deep lakes with smaller, shallow ones. Relative littoral area (-0.8339) had a strong negative correlation with PC2, which contrasted lakes with high versus low littoral area; lakes with intermediate PC2 scores had a good mix of both littoral and pelagic habitat .

Both SP and NSP lake values occurred across the range of lake sizes (PC1) and amount of relative littoral area (PC2) with no obvious differentiation between SP and NSP lakes (Figure 4; 
Appendix C). Using the Jolliffe stopping rule the first two PCs were retained. There were no significant differences in mean scores for SP and NSP lakes along PC1 $\left(t=0.072_{12}, \mathrm{p}=0.94\right)$ or $\operatorname{PC} 2\left(t=0.0015_{12}, \mathrm{p}=0.99\right)$.

The Hotelling's $\mathrm{T}^{2}$ test for differences in group centroids on PC axes (PC1 and PC2) was not significant ( $\mathrm{p}=0.67$ and $\mathrm{p}=0.99$, respectively) so no discriminant function analysis (DFA) was attempted.

\section{Chemical comparisons among lakes}

Species pair and NSP lakes showed near significant differences in conductivity $\left(\mathrm{F}=5.268_{7.802}, \mathrm{p}\right.$ $=0.052 ;$ Figure 5), dissolved inorganic carbon $\left(F=5.05_{6.656}, \mathrm{p}=0.056\right.$; Figure 5), total dissolved solids $\left(F=5.02_{7.784}, p=0.062\right.$; Figure 6$)$ and alkalinity $\left(F=4.272_{7.174}, p=0.077\right.$; Figures 6$)$. While SP lakes as a group had higher mean values for these variables than NSP lakes, it was not a definitive factor for discriminating SP lakes because Little Quarry Lake (a species pair lake) had one of the lowest values for all four of these water chemistry variables (Figure 5 and 6).

Principal component 1 and PC2 accounted for $43.5 \%$ and $24.7 \%$, respectively, of the total variance in the water chemistry data set. Principal component 1 showed a strong negative correlation with dissolved oxygen in the hypolimnion (-0.3152) and a strong positive correlation with total organic carbon (0.317), total nitrogen (0.3048), and dissolved organic carbon (0.3014). Principal component 2 had a strong negative correlation with coloured dissolved organic matter (-0.3216) and strong positive correlations with water transparency (0.3493), alkalinity (0.3266), dissolved inorganic carbon (0.3223), conductivity (0.3213), and total dissolved solids (0.3171). 
While SP lakes cover a larger spread on PC2, they are not obviously differentiated from NSP lakes or restricted to any part of the ordination (Figure 7; Appendix D). Principal component 3 was most strongly correlated with mean temperature (0.5135), mean dissolved oxygen (0.4548), temperature in the epilimnion (0.3295), and temperature in the hypolimnion (0.3068).

The Jolliffe stopping rule resulted in the first five PCs being retained. Across all five PCs, there was a significant difference in the mean scores between SP and NSP lakes for only PC3 $(\mathrm{t}=-$ $\left.2.52_{12}, \mathrm{p}=0.027\right)$. The Hotelling's $\mathrm{T}^{2}$ test using the PC axes (PC1 to PC5) was marginally significant $(\mathrm{p}=0.054)$ and the subsequent DFA classified the lakes correctly as SP or NSP lakes with an accuracy of $85.7 \%$ after using the leave-one-out method.

\section{Biological comparisons among lakes}

There was no significant difference in total macrophyte abundance between SP and NSP lakes ( $\mathrm{t}$ $=-0.39_{12}, \mathrm{p}=0.70$ ). Macrophytes showed a range of $0.2 \%$ to $30.5 \%$ for SP lakes and $0.02 \%$ to 77.9\% for NSP lakes (Figure 8, Appendix A). Species pair and NSP lakes were similar in biomass for both invertebrates in sediment $\left(t=0.98_{12}, \mathrm{p}=0.35\right)$ and invertebrates on rock $(t=$ $\left.0.62_{12}, \mathrm{p}=0.55\right)$

For the principal components analysis, PC1 and PC2 accounted for 52.9\% and $28.6 \%$, respectively, of the total variance. Principal component 1 was strongly correlated with submergent macrophytes $(0.4681)$, invertebrates on rock $(0.4493)$, total macrophytes $(0.4106)$, invertebrates in sediment (0.3991), zooplankton (0.3847), and emergent macrophytes $(0.3211)$. Principal component 2 showed a strong positive correlation to emergent macrophytes $(0.6225)$ 
and total macrophytes $(0.515)$ and a strong negative correlation to zooplankton $(-0.4279)$ and invertebrates in sediment (-0.3769). No obvious patterns were resolved between SP and NSP lakes (Figure 9; Appendix E). Following the Jolliffe stopping rule, $t$-tests were performed on the first three PCs and all were shown to be non-significant (all $p>0.05$ ). Hotelling's $\mathrm{T}^{2}$ test was not significant using the PC axes (PC1 to PC3) ( $\mathrm{p}=0.66)$ so no DFA was attempted.

\section{Comparison among lakes with all variables combined}

Principal component 1 and PC2 accounted for $35.5 \%$ and $20.5 \%$, respectively, of the total variance. Principal component 1 showed a strong positive correlation with dissolved oxygen in the hypolimnion $(0.2667)$, and a strong negative correlation with total nitrogen $(-0.2701)$, total organic carbon (-0.2563), and dissolved organic carbon (-0.2471). Principal component 2 was most strongly correlated with water transparency (0.3186), chlorophyll a (-0.2977), and coloured dissolved organic matter (-0.2833). Principal component 2 was also strongly correlated with zooplankton (0.2488), conductivity (0.2472), dissolved inorganic carbon (0.247), alkalinity (0.2449), and total dissolved solids (0.2446). Again, no obvious patterns are shown between SP and NSP lakes (Figure 10; Appendix F). Following the Jolliffe stopping rule, the first eight PCs were kept, but no significant differences between SP and NSP lakes were observed (all p > 0.05). Hotelling's $\mathrm{T}^{2}$ test using PC axes (PC1 to PC8) was also not significant $(\mathrm{p}=0.49)$ and no DFA was attempted.

\section{MCLUST analysis}

The Jolliffe stopping rule was used to determine the number of PCs to retain $(\mathrm{N}=8)$ for the combined data. A MCLUST analysis was performed on these first eight sets of PC scores from 
the combined data set of all physical, chemical, and biological variables (Figure 10). This analysis showed that the best model to explain the data was six components (i.e., groups of lakes) with equal ellipsoidal shapes and with equal variance within groups of lakes, i.e., lake groups are of equal volume, equal shape, and equal orientation. These six components or groups contain the following lakes: 1) Emily Lake 2) Priest Lake 3) Paxton Lake 4) Chemainus Lake 5) North, Brown, and Little Quarry lakes, and 6) Balkwill, Enos, Hadley, Cranby, Weston, Stowell, and Ambrose lakes (Figure 11). Lakes did not appear to group according to SP vs. NSP lakes (Table 1), geography (Table 1, Figure 2), underlying geology (British Columbia Ministry of Energy Mines and Petroleum Resources 2004 and Table 2), other measured physical attributes (Appendix A), or fish community (Table 1, Figure 12).

\section{Fish community comparisons among lakes}

The single linkage dendrogram formed four clusters of lakes according to fish species composition; cluster 1 includes six SP lakes, Paxton, Emily, Balkwill, Priest, Enos, and Hadley lakes, and one NSP lake, Cranby Lake, cluster 2 includes NSP lakes containing rainbow trout, Chemainus, Stowell, and Weston lakes, cluster 3 includes NSP lakes containing prickly sculpin, North, Brown, and Ambrose lakes, and cluster 4 includes an SP lake with no fish other than stickleback, Little Quarry Lake (Figure 12). Clusters one, two, and three were $66.7 \%$ similar to each other while cluster four was $50 \%$ similar to all other clusters (Figure 12). 


\section{Discussion}

\section{Differentiation between lake types}

One of the key factors thought to be involved in rapid population divergence of a lineage into different morphs is low competition from trophically similar species, which presumably allows the diverging population to expand into new and underutilized microhabitats (i.e. open niches; Schluter 2000). For example, Icelandic Arctic char can be found in lakes as either a single morph or with up to four different eco-morphs. The factors allowing/driving this divergence are thought to be a combination of resource heterogeneity and low species diversity and therefore low interspecific competition (Skulason and Smith 1995; Knudsen et al. 2007). Indeed, the lake supporting four eco-morphs of Arctic char has a very heterogeneous environment and a depauperate fish community containing only Arctic char, threespine stickleback, and a small population of brown trout (Salmo trutta; Sandlund et al. 1987; Smith and Skulason 1996). This can be seen in other fish species (Taylor 1999) as well as in other vertebrates such as lizards (Losos 1997) and some birds (Grant and Grant 2002).

The repeated parallel evolution of stickleback species pairs and their geographically clustered location suggests that there are deterministic factors involved in stickleback divergence rather than species pairs existing in certain lakes by chance alone (e.g., Schluter and McPhail 1992). This supports the hypothesis that a specific suite of abiotic and/or biotic lake attributes are required for species pair occurrence, as opposed to the alternate possibility that random colonization by sticklebacks account for where species pairs occur. As such, the goal of my 
study was to determine if specific environmental factors are important determinants of divergence of the stickleback species pairs and, by inference, important for their persistence.

The results of this study may have been affected by the damming of all SP and some NSP lakes (pers. obs.). Through the damming of these lakes, water levels may have been raised or lowered thereby altering the natural lake levels and littoral habitat available to fishes as well as changing the concentration of organic material within each lake. Further, dams may have affected fish species currently present within the lakes by blocking access to lakes and stream beds used as spawning grounds by salmonids. It has also been suggested that the stickleback speciation may be a more recent consequence of the dams themselves (Chris Wood and Clyde Murray, DFO, pers. comm.). Under this scenario, each lake would have had a lake morph and a stream morph before the dam went in and the addition of the dam caused some stream morphs to be isolated within the lake. These stream and lake morphs would have then differentiated into benthic and limnetic species through character displacement. This idea, however, is unlikely as the dams are less than 100 years old and the species pairs appear to have diverged between 5000 and 18000 years ago (E.Taylor, pers.comm; unpub data).

It was expected that SP lakes would have a broader spectrum of prey resources than NSP lakes, thus providing more opportunity for sticklebacks to diverge into limnetic and benthic forms. My results, however, showed a similar range of benthic and pelagic resources in SP and NSP lakes. The second expectation that the amount of littoral and pelagic habitat types would differ between SP and NSP lakes was also not supported, as both lake types had comparable amounts of littoral and pelagic habitat types as measured by relative littoral area and macrophyte abundance. My 
analysis, therefore, suggests that SP and NSP lakes have similar ranges in resource abundance and habitat structure. By contrast, my data showed that fish communities differed strongly between SP and NSP lakes: the former were found to contain only stickleback, or stickleback and coastal cutthroat trout. Consequently, it appears that fish community is a major ecological determinant of whether species pairs are found in lakes in coastal B.C.

A greater abundance and diversity of fish species may increase both competition and predation, limiting the scope for stickleback diversification. While cutthroat trout are both piscivorous and benthivorous as adults when they occur without other large predators, they can become more piscivorous when they coexist with rainbow trout (Nilsson and Northcote 1981). Consequently, in lakes where adult cutthroat and rainbow trout are both present, stickleback may be preyed upon heavily in the pelagic zone by coastal cutthroat trout. To reduce the risk of predation it is common for small prey species, such as stickleback, to inhabit areas with more habitat structure, such as the littoral zone (e.g. Walters and Juanes 1993). This coupled with competition for zooplankton with juvenile coastal cutthroat trout and rainbow trout may have prevented stickleback from becoming fully pelagic in some lakes. In the littoral zone of NSP lakes, stickleback are susceptible to competition and predation from adult coastal cutthroat trout and rainbow trout, as well as adult prickly sculpin which prey both on adult stickleback and their eggs (Pressley 1981). In addition, if competitors for either zooplankton (e.g. juvenile salmonids) or benthos (e.g. prickly sculpin) are more efficient at exploiting these resources, this would reduce resource abundance and decrease per capita resource availability to either benthic or limnetic stickleback thereby lessening the intensity of any divergent selection. These pressures may have kept stickleback from becoming fully benthic and caused selection for a form that is 
intermediate in resource and habitat use. As such, my results suggest that the absence of interspecific competition and predation were key factors that may have promoted diversification through character displacement by intraspecific resource competition. This is in agreement with findings by Vamosi (2003) who did a similar study of species composition in stickleback lakes but considered fewer variables (water chemistry, prey abundance and macrophytes were not included). Vamosi (2003) compared six SP lakes to 16 NSP lakes and found that all but one NSP lake contained other fish besides stickleback and coastal cutthroat trout, leading Vamosi to suggest that stickleback divergence into species pairs is more likely to occur in lakes colonized by only stickleback and coastal cutthroat trout.

A similar case is presented by Landry et al. (2007) who compared environmental factors of highly differentiated lake whitefish species pair lakes to those of less differentiated species pair lakes as determined by differences in gill raker counts. While this is a slightly different question to the one asked in the present study, it represents a similar situation as lake whitefish occur as species pairs only in the absence of lake cisco (a direct pelagic competitor) while stickleback species pairs coexist only with coastal cutthroat trout or when no other fish species are present. Thus, in both lake whitefish and stickleback species pair systems the fish community is depauperate and the lack of heterospecific competitors could promote expansion and persistence into new and open niches. Indeed, Lindsey (1981) concluded that the presence of benthic and limnetic forms of lake whitefish may be due to, and change in response to, the presence or absence of other fish species. 
Landry et al. (2007) also found that lakes with more highly differentiated lake whitefish species pairs had reduced habitat (lower hypolimnetic $\mathrm{O}_{2}$ ) and zooplankton availability (lower density and length) and suggested that this would increase intraspecific competition for resources. My study, however, found similar zooplankton availability (biomass) across SP and NSP lakes. It appears, therefore, that while differences in resource abundance may promote divergence in some lineages and areas, it does not appear to be a general factor determining where species pairs can occur, at least in stickleback. It is also possible that differences seen by Landry et al. (2007) between lake groups could be a result of fish species altering attributes of the environment rather than the environment altering the fish species (e.g. Harmon et al. 2009; Bassar et al. 2010).

One difference observed between attributes of stickleback SP and NSP lakes was in the values of conductivity, total dissolved solids, dissolved inorganic carbon, and alkalinity which were nearly significantly higher in SP lakes. Despite this apparent differentiation, both the highest and lowest, or next to lowest, value measured for each of these variables occurred in a SP lake, thus making this difference unlikely to be the primary driver of species pair occurrence (i.e., while it suggests that species pairs may be more likely to occur in more productive lakes based on water chemistry, it is not a necessary precondition for their evolution).

\section{Origin and persistence of species pairs}

The results of my study support the idea that low species diversity can promote rapid population divergence (Schluter 2000). My results also suggest that there are no obvious limnological features amongst those I measured that appear to be a precondition for species pair evolution. 
This general result implies that some aspect of the history of the lakes might be important to species pair formation. One such possibility is the notion that multiple invasions of the lakes (and how colonization is influenced by local geology, elevation, etc) by different groups of sticklebacks has been an important historical factor influencing the distribution of species pairs (McPhail 1993: Taylor and McPhail 2000). In addition, the geographic history of the lakes is important when considering what other species have been able to access the lakes which, as my results and those of Vamosi (2003) suggest, probably has been an important ecological factor in species pair formation. Further, my results suggest that, with regards to conservation, a critical factor in the persistence of species pairs is conserving the current species composition (i.e. keeping invasive species out), rather than forming specific abiotic environmental management criteria. The collapse of the Enos Lake species pair into a hybrid swarm following the appearance of the American signal crayfish (Kraak et al. 2001; Taylor et al. 2006) and extinction of the Hadley Lake species pair following the introduction of the brown bullhead (Hatfield 2001) are examples of the devastating impact that invasive species can have on stickleback species pairs. That being said, habitat loss and degradation is the number one threat to freshwater fishes in Canada and the effect of invasive species is often compounded by habitat change (Dextrase and Mandrak 2006). Consequently, although I cannot point to one critical habitat feature or combination of habitat features that sustain species pairs, it is likely that any degradation or loss of habitat in existing SP lakes would compromise the persistence of benthic and limnetic sticklebacks. Although the SP lakes may not have unique limnological attributes relative to NSP lakes, water quality (e.g. dissolved oxygen, nutrients, turbidity) needs to be maintained within an appropriate range for the tolerance of the species (National Recovery Team for Stickleback Species Pairs 2007). 
The situation in Enos Lake highlights the connection between the environment and its inhabitants as well as the adaptability of the stickleback. Enos Lake was, at one time, known to be a stickleback SP lake containing only a sympatric pair of stickleback and coastal cutthroat trout (McPhail 1984). Recently the species pair in Enos Lake has collapsed into a hybrid swarm (Kraak et al. 2001, Taylor et al. 2006) coincident with the invasion of the American signal crayfish, which is thought to be an important factor driving this hybridization. Although the crayfish may cause direct effects on stickleback through predation or mating disruption (Velema 2010), indirect effects of crayfish through alteration of habitat by destruction of macrophytes, changes in water clarity, or reduced invertebrate abundance are equally likely (Taylor et al. 2006). Indeed, Rosenfeld et al. (2008) conducted an enclosure experiment over a 38 day period to determine the impact, if any, that crayfish have on macrophytes and found that macrophytes within enclosures containing crayfish decreased in overall abundance by approximately $50 \%$ showing that crayfish can reduce macrophyte abundance considerably in a relatively short period of time.

Freemark and Merriam (1986) showed that increased habitat heterogeneity was linked to an increase in number of species and pairs of birds present in temperate forests as more habitat differentiation permitted coexistence of specialized species. Likewise, macrophytes contribute to the habitat heterogeneity of lakes and may be contributing to species diversity and species richness. Macrophytes provide cover for juvenile and adult benthic stickleback, nesting material for benthic reproduction, and habitat for macroinvertebrates. Thus, food resources in the littoral zone may shift in the absence of macrophytes as certain macroinvertebrate species that are dependent on macrophytes in their life cycle will probably not occur in high abundance (e.g. 
Sahlen and Ekestubbe 2001). Loss of macrophytes could also potentially cause a breakdown in microhabitat between limnetic and benthic stickleback, which overlap in their mating areas. Both limnetic and benthic stickleback breed in shallow littoral zones at the same time of year; limnetics in open rocky areas and benthics in densely vegetated areas (McPhail 1994). The removal of macrophytes removes a possible environmental reproductive barrier used by the two species during mating and therefore may increase the frequency of interactions and hybridization. Indeed, Hatfield and Schluter (1996) tested sexual selection in a lab setting and concluded that there is no disadvantage to hybrid mating and therefore any sexual selection against hybrids in the wild must be due to some environmental factor that reduces the encounter rate between limnetic and benthic species. Vamosi and Schluter (1999) added further evidence through an enclosure experiment in the wild with limnetic sticklebacks and $F_{1}$ hybrid males, finding that $F_{1}$ hybrid males had less mating success than limnetic males possibly due to habitatspecific selection pressures.

The exact environmental conditions of Enos Lake prior to the collapse of its stickleback into a hybrid swarm are unknown. McPhail (1984), however, documented that the littoral zone was densely covered with submergent macrophytes. This is in stark contrast to the observations of this study completed in summer of 2008 , which found that while the lake had a relative littoral area of $47.8 \%$ only $0.1 \%$ of the total lake surface area was covered by submergent macrophytes and a further $0.1 \%$ covered by emergent macrophytes. It, therefore, appears that macrophyte abundance has changed dramatically since the Enos Lake species pair was first documented. 
Interestingly, in Little Quarry Lake, only $2.0 \%$ of the entire lake surface area was covered by macrophytes and in Balkwill Lake only $1.2 \%$ was covered by macrophytes. This indicates that species pairs can persist in an environment with relatively few macrophytes and that the change in macrophyte abundance in Enos Lake, while possibly contributing to hybridization, may not be the only factor promoting hybridization.

My results can also contribute to the debate about whether or not crayfish may have influenced water clarity and, therefore, altered mate selection regimes in Enos Lake. Seehausen et al. (1997) showed that the frequency of hybridization between some species of cichlid fishes was higher when light transmission was altered to the extent that it impairs mate discrimination. In environments with reduced visibility random mating may occur more often than selectively choosing mates as the chance of encountering specific individuals is lower and therefore hybridization rates can increase (Seehausen et al. 2006). This is particularly true for stickleback species pairs as benthic and limnetic stickleback differ in their breeding colouration and these colours are used as cues for mate recognition and are therefore a reproductive barrier (Boughman 2001). My study, however, showed that in Enos Lake turbidity, light extinction, and various other water chemistry values that affect water clarity all fall within the range of other relatively unperturbed SP lakes. This comparison suggests, therefore, that alteration of water clarity was not likely a factor in increased hybridization rates in Enos Lake at the time of data collection.

Critical habitat with regard to stickleback species pairs includes not only the habitat needed to ensure survival both of benthics and limnetics, but also the features of the environment that 
promote segregation in mating (Rosenfeld and Hatfield 2006; National Recovery Team for Stickleback Species Pairs 2007; Hatfield 2009). As SP lakes were not significantly different from NSP lakes with regard to their suite of environmental characteristics, the main management goal would be to maintain stickleback species pair lakes within their current values of all environmental parameters measured, particularly those that act as reproductive barriers as these species pairs are not completely reproductively isolated (McPhail 1994; Gow et al. 2006). Significant alterations to water quality or nutrients from their current levels could potentially be detrimental to the species pairs by changing the abundance and/or type of food resources available and therefore altering selection pressures on stickleback (Futuyma and Moreno 1988; Behm et al. 2010). Urbanization and human activities should also be regulated as they can lead to sedimentation, eutrophication, and fluctuations of water levels which alter the amounts of littoral and pelagic habitats available to stickleback and their resources. My study now provides baseline data for all known SP lakes to facilitate environmental monitoring of lake conditions and provides detailed environmental data for lakes that support healthy species pairs as well as for lakes that appear to favour the intermediate form (Enos Lake). 


\section{Chapter 3 - General Discussion}

\section{Contributions to the field}

A large amount of research regarding threespine stickleback species pairs evolution has been conducted, but there has been relatively limited empirical information on the limnological environment the species pairs occupy (Schluter and McPhail 1992; Vamosi 2003). The majority of work has focused on the genetics, morphology, behaviour, and physiology of the species pairs while the present work provides the first in depth study on the physical, chemical, and biological aspects of the environment, which can be useful in further studies in evolutionary ecology and for the management and conservation of SP lakes. While no specific environmental parameters were shown to be unique to SP lakes, my work indicates that the main impacts to species pairs could be the community of fish present in the lakes and that nesting habitat heterogeneity and its influence on reproductive barriers may be important to the persistence of these species pairs (Rosenfeld and Hatfield 2006; National Recovery Team for Stickleback Species Pairs 2007; Hatfield 2009). My thesis suggests that the fish assemblage in stickleback lakes (and lakes in general) may affect resource availability as strongly as the limnological attributes of the lake itself although predation may also be an important factor in the evolution of these species pairs (Vamosi 2001).

Although my work does not suggest that SP lakes are unique with regards to the environmental parameters measured, it does provide a baseline for conditions that relatively unperturbed species pairs live in. So while critical thresholds for the maintenance of the species pairs for the various criteria measured may not be known, what is now known is the acceptable level of the measured 
criteria for species pairs to thrive. As such, use of the lakes, such as water extraction, riparian zone use, or any other human activities that could cause changes in nutrient levels, water clarity, resource abundance, or alter habitat structure should be regulated to maintain lakes within their current range for environmental parameters measured in this study. The greatest current concern to the species pair lakes is the risk of invasive species being introduced as evidenced by the Hadley Lake extinction and the Enos Lake collapse (Hatfield 2001; Kraak et al. 2001; Taylor et al. 2006). Regular monitoring of species pair lakes will ensure that any detrimental activities taking place within SP lakes or their watersheds will be discovered early, and may help minimize their impact on the SP lakes; however, even if monitoring detects invasive species in a timely fashion, eradication or control is difficult to impossible, and the management priority has to be keeping them out of species pair lakes in the first place. Also important is providing education to the public regarding the uniqueness and life history of the stickleback species pairs and factors thought to be important to their persistence, as well as general aspects of aquatic ecology to hopefully instil awareness and appreciation of these and other fish and their environment.

The results of my study and the observations of the collapse of the species pairs in Enos Lake point to the importance of pre-mating reproductive barriers in evolutionarily young species where reproductive isolation is maintained largely by habitat segregation or mate choice (e.g., Seehausen et al. 1997; Knight et al. 1998; Patten et al. 2004). In the case of the stickleback this pre-mating reproductive barrier may be macrophytes as benthics nest in macrophytes and limnetics prefer to nest in open areas without macrophytes (McPhail 1994). Closely related relatively young species can often hybridize to produce viable, fertile offspring because irreversible post-mating reproductive barriers have not yet developed (e.g. Seehausen 1997). As 
such, identifying the ecological attributes of the environment that promote segregation in mating between closely related species is important to the maintenance of such species. Baseline studies such as this one provide important information that can be used to identify the habitat needs of a species and also provide information on the selection pressures in the local environment. This type of study would be of value to any rare and recently evolved species as it is directly applicable to conservation efforts and has the potential of leading to targeted management practices specific to the conservation of individual species at risk.

In a similar study, Landry et al. (2007) suggested that low oxygen in the hypolimnion could be an important factor that explains why some lakes contain more divergent pairs of benthic pelagic (normal - dwarf) lake whitefish than others. In my study I did not find levels of hypolimnetic oxygen to be significantly different between stickleback SP or NSP lakes. The lakes examined by Landry et al. (2007) appear to fall within the same ranges as my study lakes for all productivity variables that were common to both studies, including hypolimnetic oxygen. As such this may be a property of how divergent a species pair can become rather than whether or not a species pair can arise at all. Oxygen may be more of a key segregating factor in lake whitefish SP lakes when compared to stickleback SP lakes because the normal lake whitefish ecotype inhabits the deepwater profundal zone (Scott and Crossman 1973). Thus depleted oxygen in deeper waters could limit the number of individuals supported and possibly cause individuals to seek out new habitat (e.g., dwarf whitefish in the pelagic zone). In contrast, the stickleback inhabits the pelagic zone and littoral zone which may have greater oxygen than the profundal zone due to wind mixing and photosynthetic phytoplankton and macrophytes (Wetzel 
2001) and is, therefore, not usually limited in oxygen supply and not likely to be a segregating factor between benthic-limnetic sticklebacks.

\section{Strengths and limitations of research}

Non-species pair lakes were chosen based on their elevation, distance to the sea, and fish community. While all NSP lakes fall within the same range of elevation and distance to sea as SP lakes, only one NSP lake had a similar fish community (Cranby Lake). The other NSP lakes included one or more additional fish species (i.e. beyond coastal cutthroat trout) and thus SP and NSP lakes represent slightly different adaptive landscapes. Although it would have been ideal to control for fish community structure and sample lakes that were exactly the same (i.e., had only stickleback and cutthroat trout), the difference in fish community structure between SP and NSP lakes highlights the potential role of interspecific competition, open niches, and predation in the speciation of stickleback species pairs, and strengthens the inference that fish community composition is more important than abiotic attributes in facilitating speciation.

My field work consisted of an intensive eight week (July-August) collecting period in which I sampled all environmental parameters from all 14 lakes followed by two seasonal sampling trips in December and April in which only one SP lake (Paxton Lake) and one NSP lake (Cranby Lake) were sampled. It would have been optimal to sample all 14 lakes in each season to obtain a full set of data to test for differences in lake attributes at all seasons, but time and resources did not allow for this. I am, however, reasonably confident that the environmental variables I measured would not be shown to be unique to SP lakes if different seasons were sampled 
because by sampling a subset of the lakes seasonally I was able to show that fluctuations in measured parameters across seasons were very similar between the SP and NSP lakes that I did sample repeatedly.

\section{Future work}

The present distribution of stickleback species pairs may not represent the complete set of lakes that experienced a double invasion by marine ancestors. It is possible that other lakes in the area were invaded twice but that the two sets of invaders hybridized upon contact rather than continued to diverge once in sympatry; or it is possible that differentiation took place, but the pair later hybridized or one of the species may have gone extinct for stochastic reasons. As such, future work could include genetic analysis of stickleback in NSP lakes to determine if they have arisen from a single or double invasion (i.e., are they hybrids?). This kind of study could also shed light on whether or not a 100 m elevation threshold is really the maximum elevation of lakes that experienced double invasion. In addition, if double invasion has occurred in lakes without current species pairs, this would add support for the idea that low fish diversity in stickleback SP lakes is a key factor in stickleback species pair divergence as current NSP lakes have greater species diversity than SP lakes, but are similar in resource abundance and abiotic attributes.

As one of the inferences from this study is that nesting habitat heterogeneity may be an important reproductive barrier to stickleback species pairs it could be useful to more thoroughly examine and define habitat breaks within SP lakes in comparison to NSP lakes. For example, mapping the presence and extent of rocky areas in relation to macrophyte beds of each lake could show 
available spawning habitat for both benthic and limnetic species as well as determining the potential overlap between the species during mating. Indeed, during my field work I noticed that not all lakes had true rocky zones and several lakes had relatively recently formed rocky zones such as that associated with the dam built in Cranby Lake. It would also be useful to sample the fish in all SP and NSP lakes to increase confidence in published fish community data.

The data collected from this study could be further used in its current form to answer other questions. For example, the present study only examined benthic invertebrate and zooplankton biomass; however, these data could be analysed for size spectra and taxa and compared between SP and NSP lakes. Following Landry et al. (2007), attributes of stickleback SP lakes could be examined according to levels of morphological divergence between limnetic and benthic species (e.g. gill raker differentiation, a common feature differentiating benthic and limnetic species pairs of various taxa (Lindsey 1981; Malmquist et al. 1992; Rogers et al. 2002). The environmental parameters measured in this study could then be correlated to the degree of differentiation between species pairs. This could potentially show whether small differences in environmental factors can increase or decrease the amount of divergent adaptation. 
Table 1. Species pair and non-species pair lakes sampled. B = smallmouth bass (Micropterus dolomeiui), $\mathrm{Ca}=$ brown bullhead catfish (Ameiurus nebulosus), $\mathrm{C}=$ coastal cutthroat trout (Oncorhynchus clarkii clarkii), $\mathrm{Sc}=$ prickly sculpin (Cottus asper), $\mathrm{S}=$ threespine stickleback (Gasterosteus aculeatus), and $\mathrm{R}=$ rainbow trout (Oncorhynchus mykiss).

\begin{tabular}{|c|c|c|c|c|c|}
\hline Lake & $\begin{array}{l}\text { Latitude } \\
\left({ }^{\circ} \mathrm{N}\right)\end{array}$ & $\begin{array}{l}\text { Longitude } \\
\left({ }^{\circ} \mathrm{W}\right)\end{array}$ & $\begin{array}{l}\text { Elevation } \\
(\mathrm{m})\end{array}$ & $\begin{array}{l}\text { Distance to } \\
\text { Sea }(m)\end{array}$ & Fish Assemblage \\
\hline \multicolumn{6}{|c|}{ Species Pair Lakes } \\
\hline Balkwill & 49.44 & 124.35 & 78 & 5000 & $S+C$ \\
\hline Emily & 49.44 & 124.32 & 31 & 3150 & $S+C$ \\
\hline Paxton & 49.42 & 124.31 & 97 & 3840 & $S+C$ \\
\hline Priest & 49.44 & 124.33 & 78 & 4720 & $S+C$ \\
\hline Little Quarry & 49.39 & 124.06 & 53 & 285 & $S$ \\
\hline Enos & 49.16 & 124.09 & 53 & 1500 & $\mathrm{~S}($ Hybrid swarm $)+\mathrm{C}$ \\
\hline Hadley & 49.29 & 124.17 & 61 & 1330 & $\mathrm{C}+\mathrm{Ca}$ (S Extinct) \\
\hline \multicolumn{6}{|l|}{ Solitary Lakes } \\
\hline Cranby & 49.41 & 124.3 & 72 & 2530 & $S+C$ \\
\hline Ambrose & 49.43 & 124.01 & 59 & 940 & $\mathrm{~S}+\mathrm{C}+\mathrm{Sc}$ \\
\hline Brown & 49.44 & 123.54 & 49 & 496 & $\mathrm{~S}+\mathrm{C}+\mathrm{Sc}$ \\
\hline North & 49.44 & 123.58 & 45 & 945 & $\mathrm{~S}+\mathrm{C}+\mathrm{Sc}$ \\
\hline Stowell & 48.46 & 123.26 & 77 & 1400 & $S+C+R$ \\
\hline Weston & 48.47 & 123.25 & 69 & 1890 & $S+C+R$ \\
\hline Chemainus & 48.54 & 123.45 & 83 & 2650 & $S+C+R+B$ \\
\hline
\end{tabular}


Table 2. Underlying rock types of all species pair and non-species pair lakes. Rock type data were collected from British Columbia Ministry of Energy Mines and Petroleum Resources (2004).

\begin{tabular}{|c|c|c|c|c|c|c|}
\hline $\begin{array}{l}\text { Underlying } \\
\text { Rock Type }\end{array}$ & $\begin{array}{l}\text { Basaltic } \\
\text { volcanic rock }\end{array}$ & $\begin{array}{l}\text { Calc-alkaline } \\
\text { volcanic rock }\end{array}$ & $\begin{array}{l}\text { Granodioritic } \\
\text { intrusive rock }\end{array}$ & $\begin{array}{l}\text { Quartzdioritic } \\
\text { intrusive rock }\end{array}$ & $\begin{array}{l}\text { Undivided } \\
\text { sedimentary } \\
\text { rock }\end{array}$ & $\begin{array}{l}\text { Limestone, marble, } \\
\text { calcareous } \\
\text { sedimentary rock }\end{array}$ \\
\hline Lakes & Balkwill (6) & Chemainus (4) & Ambrose (6) & Brown (5) & Enos (6) & Emily (1) \\
\hline (MCLUST & Cranby (6) & & Hadley (6) & North (5) & & \\
\hline Group & Paxton (3) & & Little Quarry (5) & & & \\
\hline \multirow[t]{2}{*}{ number) } & Priest (2) & & Stowell (6) & & & \\
\hline & & & Weston (6) & & & \\
\hline
\end{tabular}


A.

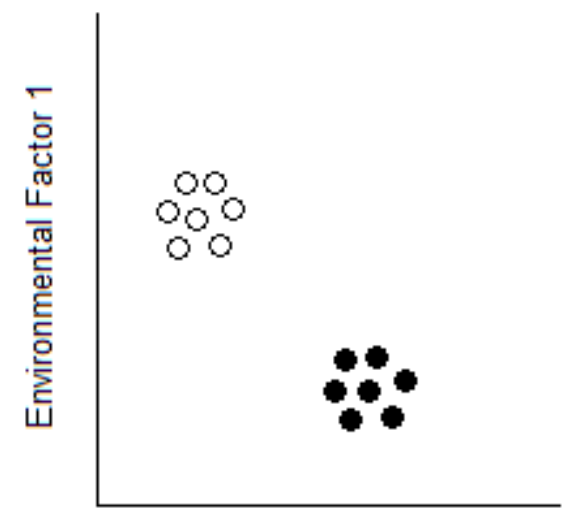

Environmental Factor 2
B.

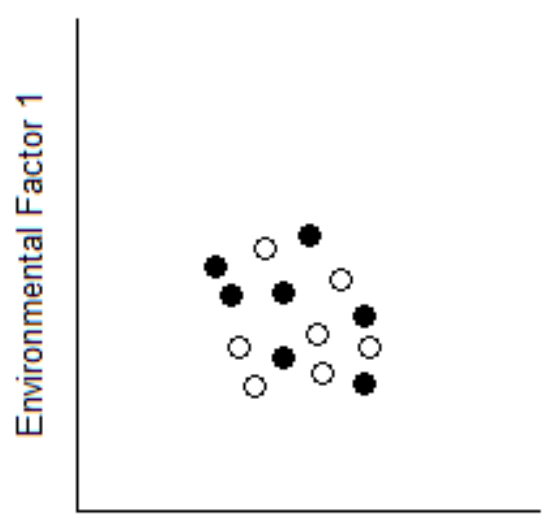

Environmental Factor 2

Figure 1. Hypothetical outcomes of two scenarios for threespine stickleback (Gasterosteus aculeatus) species pair evolution. A: supports the hypothesis of consistent environmental differences between species pair and non-species pair lakes, B: expected outcome under the null hypothesis. Open symbols represent species pair lakes; closed symbols represent non-species pair lakes. 


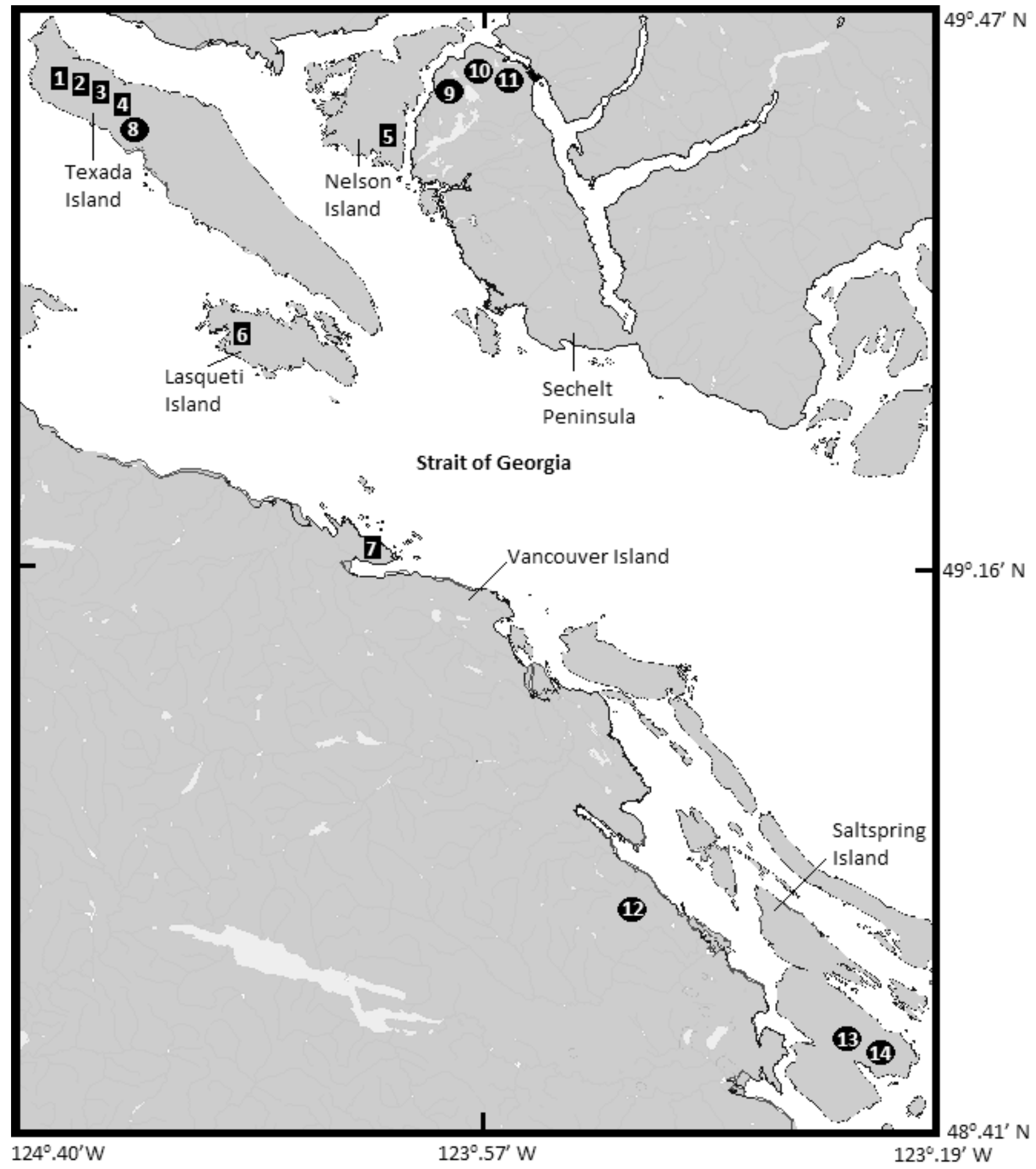

Figure 2. Map of study area. Species pair lakes are represented by rectangles; non-species pair lakes are represented by circles. $1=$ Balkwill Lake, $2=$ Priest Lake, $3=$ Emily Lake, $4=$ Paxton Lake, 5 = Little Quarry Lake, 6 = Hadley Lake, $7=$ Enos Lake, $8=$ Cranby Lake, $9=$ Ambrose Lake, $10=$ North Lake, $11=$ Brown Lake, $12=$ Chemainus Lake, $13=$ Stowell Lake, and $14=$ Weston Lake. 


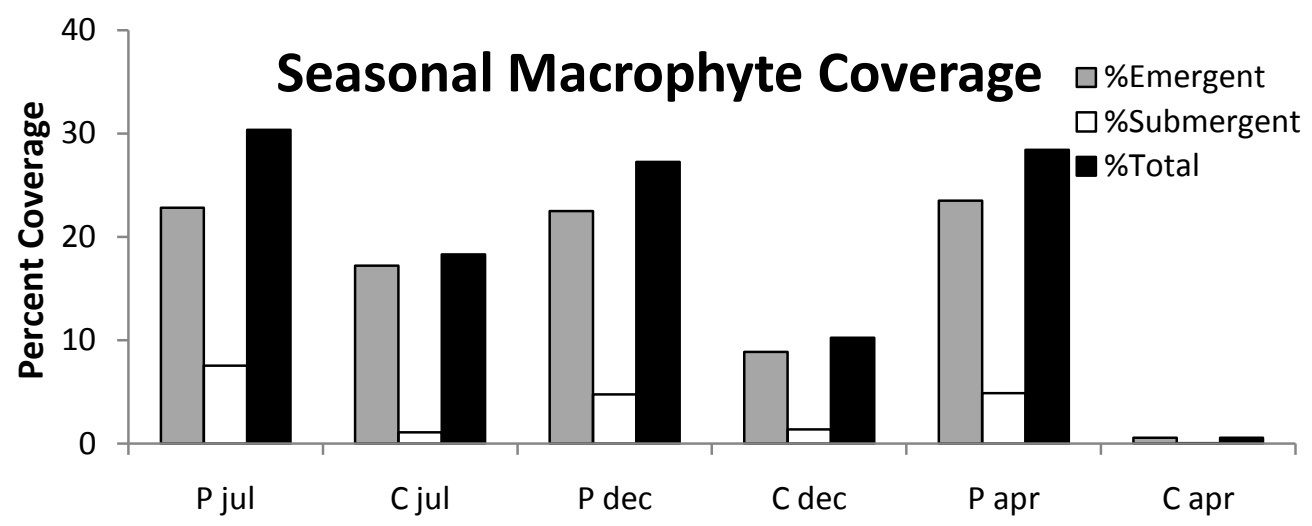

Chlorophyll a

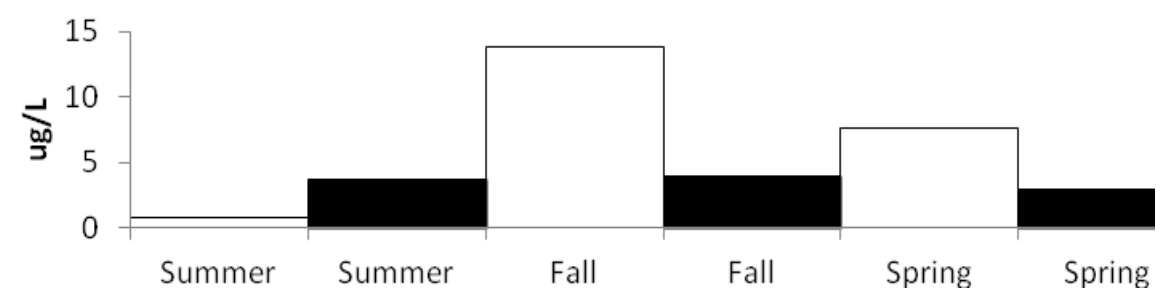

Coloured Dissolved Organic Matter

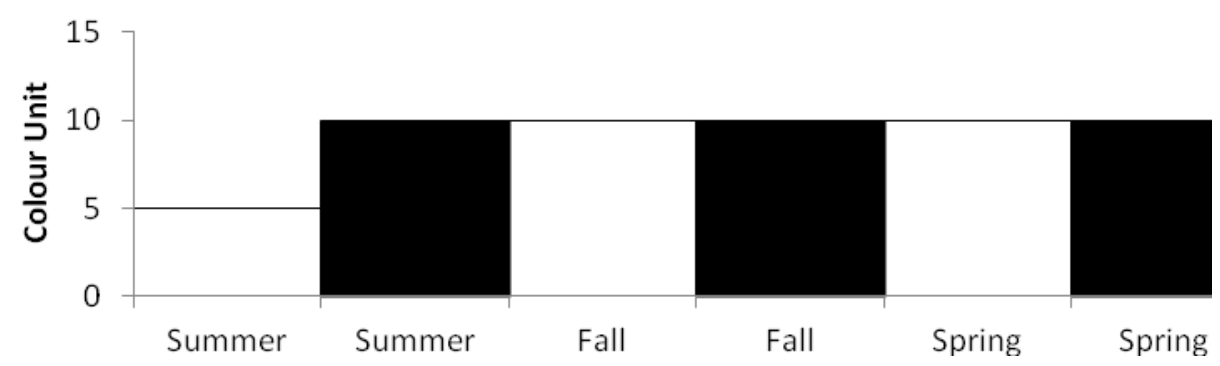

$\mathrm{pH}$

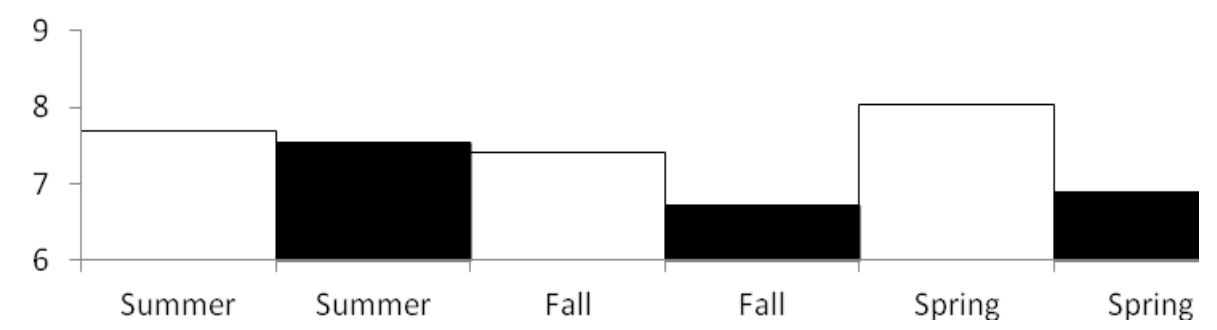

Figure 3. Bar plots of macrophyte coverage, chlorophyll a, coloured dissolved organic matter, and $\mathrm{pH}$ measured seasonally for Paxton and Cranby lakes. In the macrophyte plot Paxton Lake is represented by " $\mathrm{P}$ " and Cranby Lake is represented by "C." For the remaining plots Paxton Lake is represented by white bars and Cranby Lake by black bars. 


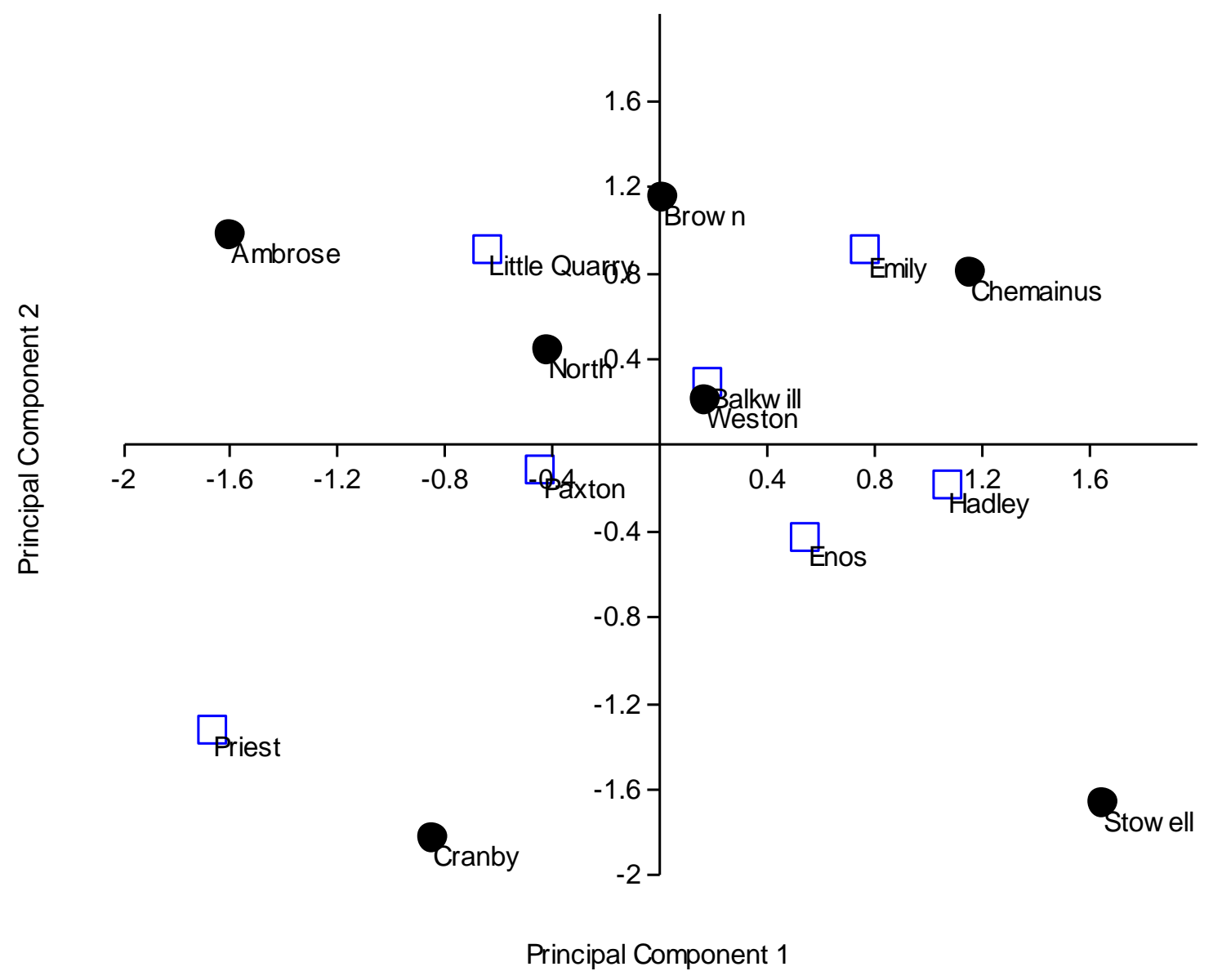

Figure 4. Scatter plot of mean scores along PC1 and PC2 for the principal components analysis of physical variables. Principal component 1 and PC2 account for $82.6 \%$ of the total variation, $55.7 \%$ and $26.9 \%$ respectively. Variables included were perimeter, surface area, relative littoral area, and maximum depth. Open squares are species pair lakes and filled circles are non-species pair lakes. 


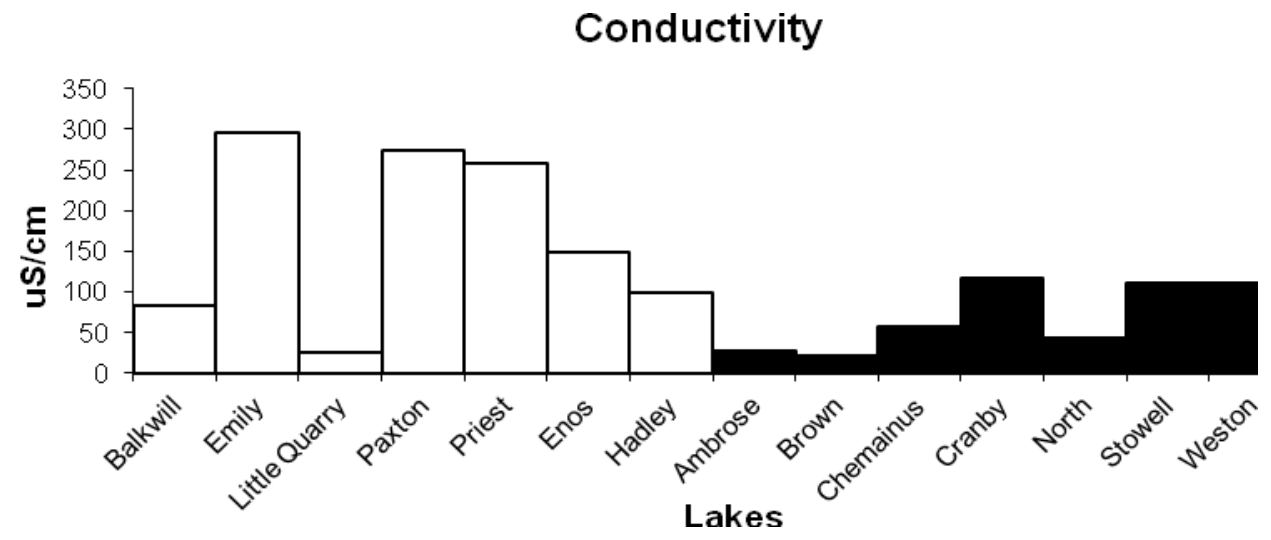

Dissolved Inorganic Carbon

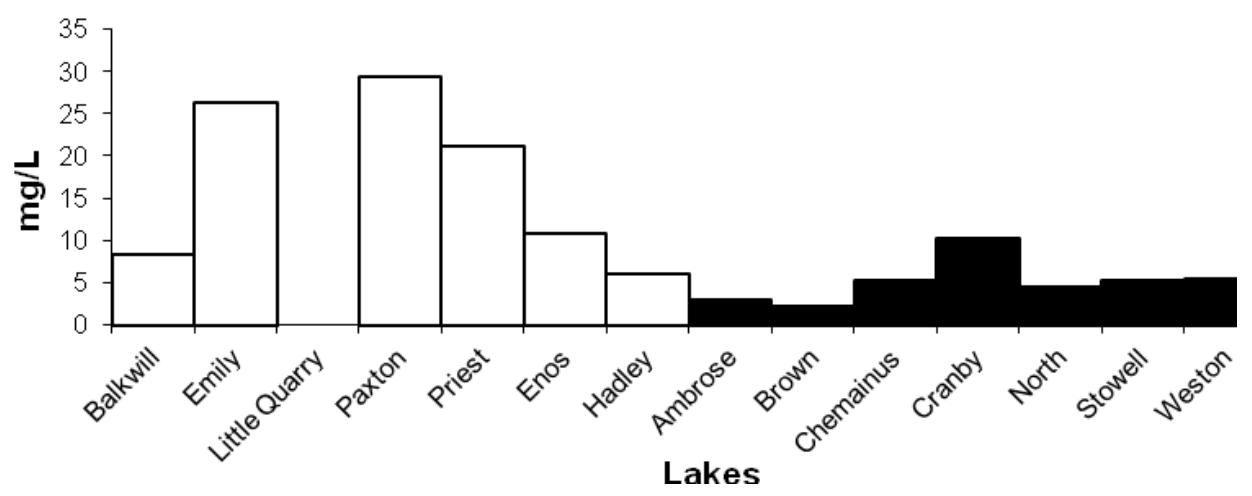

Figure 5. Bar plots of conductivity $(p=0.052)$ and dissolved inorganic carbon $(p=0.056)$ for all species pair (open bars) and non-species pair lakes (filled bars). 
Total Dissolved Solids

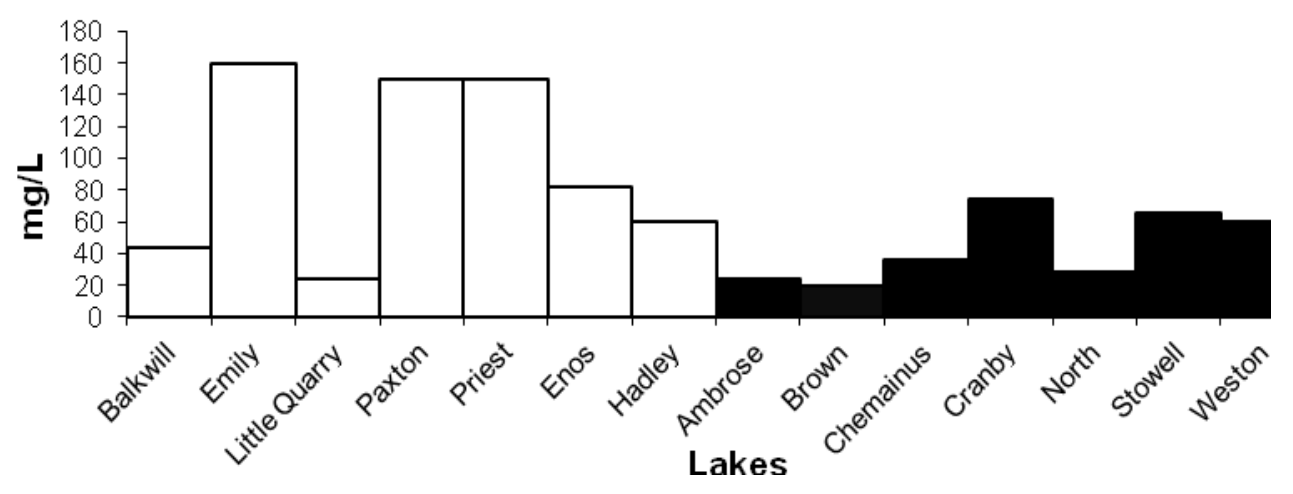

Alkalinity (Total as $\mathrm{CaCO}_{3}$ )

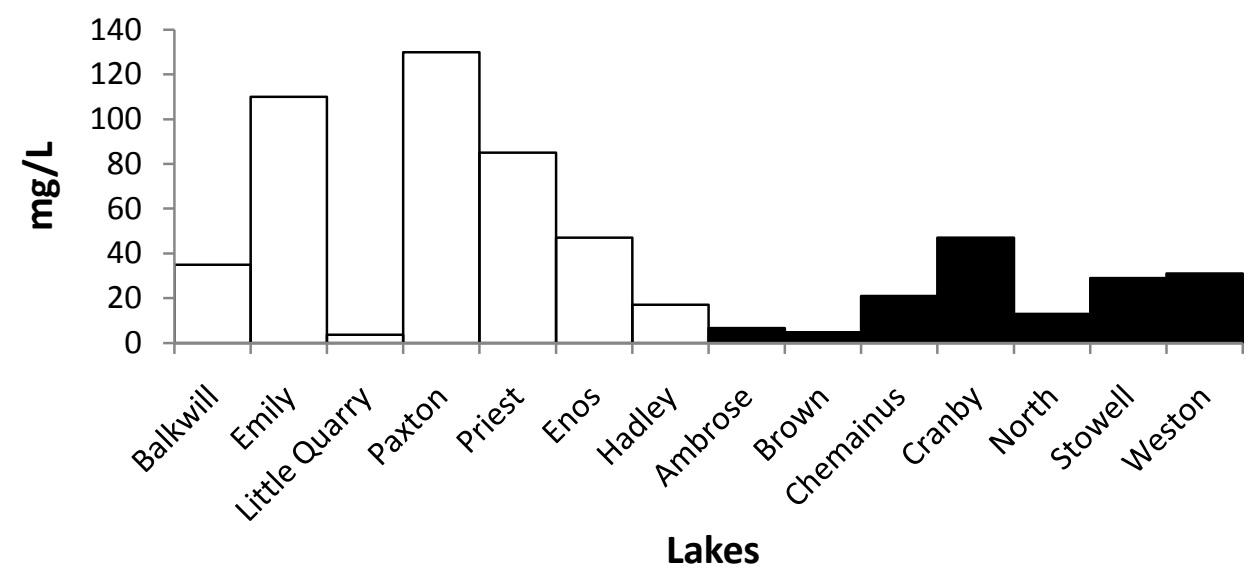

Figure 6. Bar plots of total dissolved solids $(\mathrm{p}=0.062)$ and alkalinity (total as $\mathrm{CaCO}_{3} ; \mathrm{p}=$ 0.077) for all species pair (open bars) and non-species pair lakes (filled bars). 


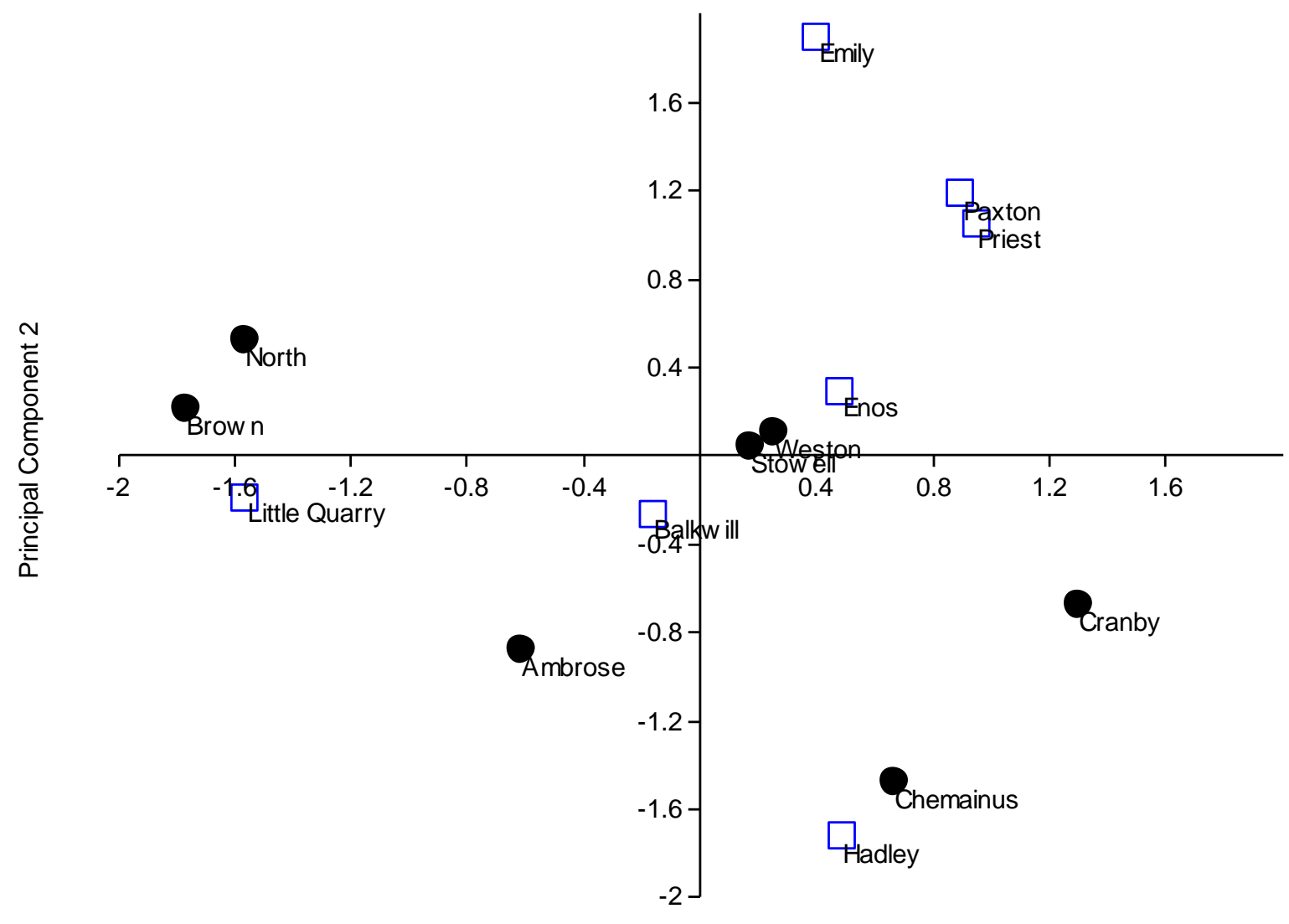

Principal Component 1

Figure 7. Scatter plot of mean scores along PC1 and PC 2 for the principal components analysis of chemical variables. Principal component 1 and PC2 account for $68.2 \%$ of the total variation, $43.5 \%$ and $24.7 \%$ respectively. Variables included were $\mathrm{pH}$, conductivity, turbidity, dissolved oxygen, temperature, water transparency, chlorophyll a, dissolved organic carbon, total organic carbon, coloured dissolved organic matter, dissolved inorganic carbon, total nitrogen, total phosphorous, alkalinity (total as $\mathrm{CaCO}_{3}$ ), and total dissolved solids. Open squares are species pair lakes and filled circles are non-species pair lakes. 


\section{Total Macrophyte Abundance}

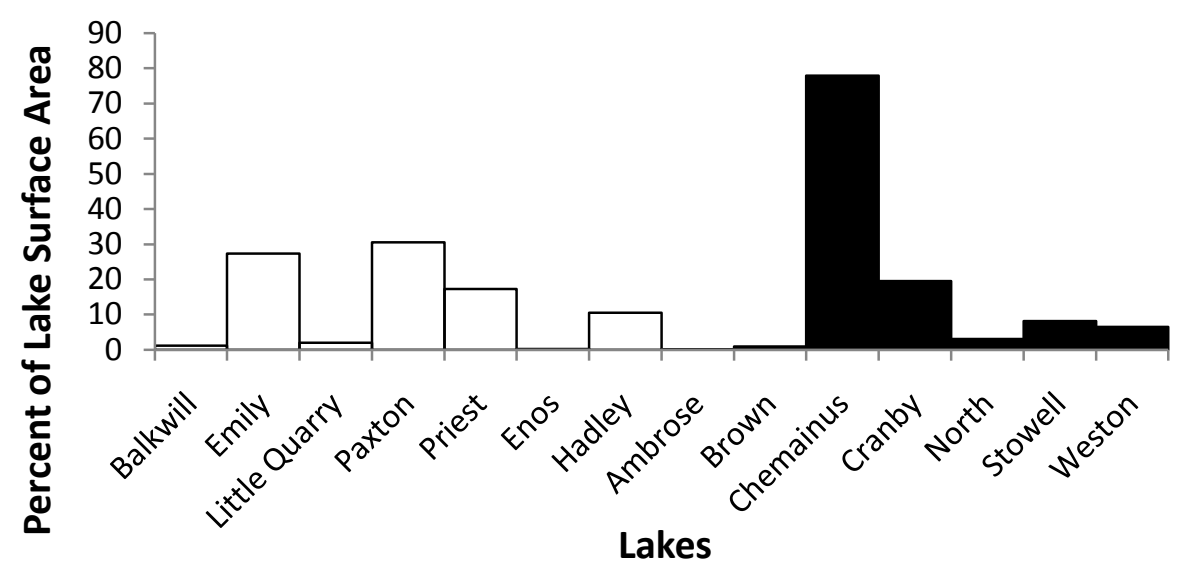

Figure 8. Bar plot of total macrophyte abundance $(\mathrm{p}=0.70)$ for all species pair (open bars) and non-species pair lakes (filled bars). 


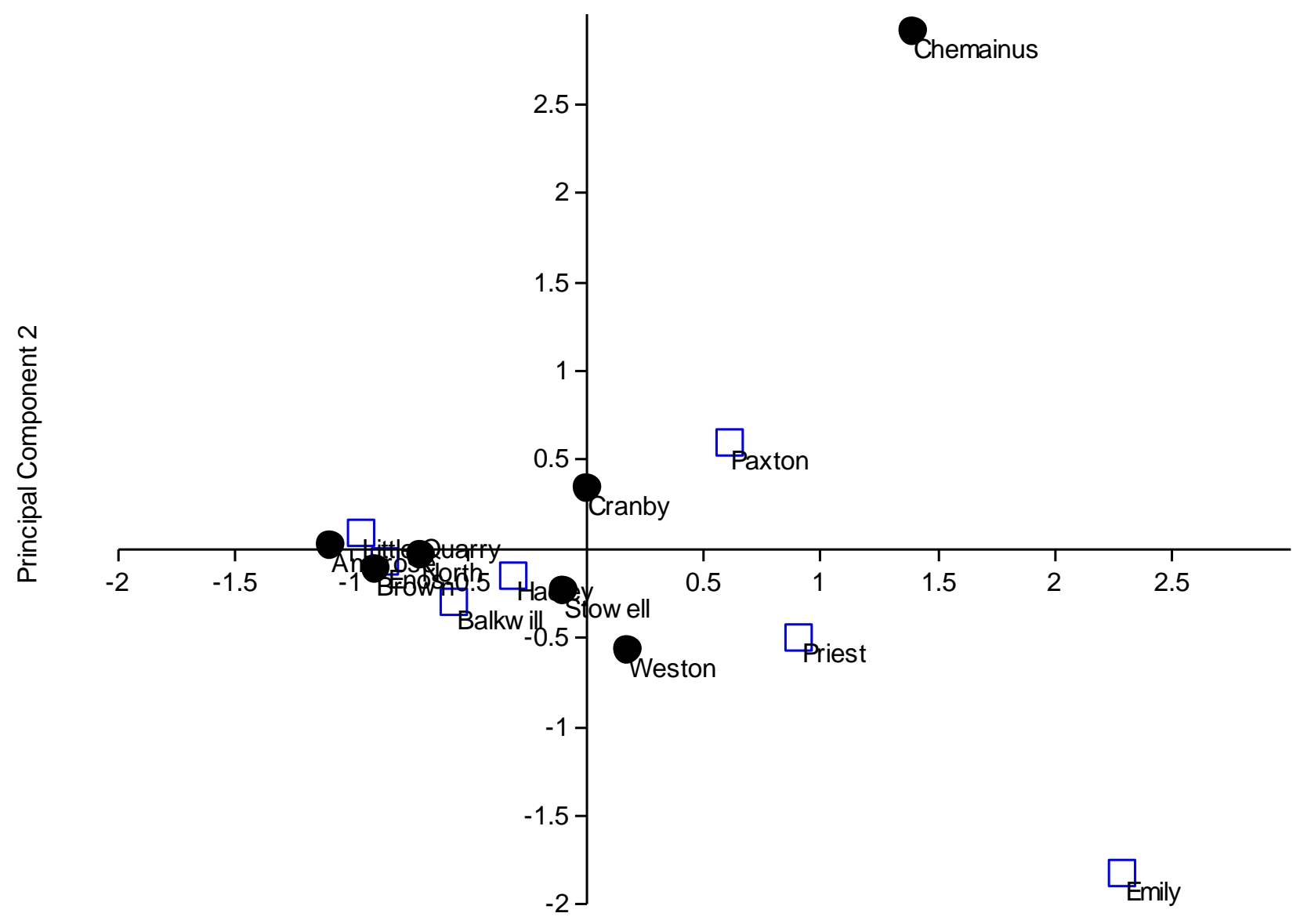

Principal Component 1

Figure 9. Scatter plot of mean scores along PC1 and PC2 for the principal components analysis of biological variables. Principal component 1 and PC2 account for $81.5 \%$ of the total variation, $52.9 \%$ and $28.6 \%$ respectively. Variables included were zooplankton biomass, invertebrates in sediment biomass, invertebrates on rock biomass, and emergent, submergent, and total macrophyte abundance. Open squares are species pair lakes and filled circles are non-species pair lakes. 


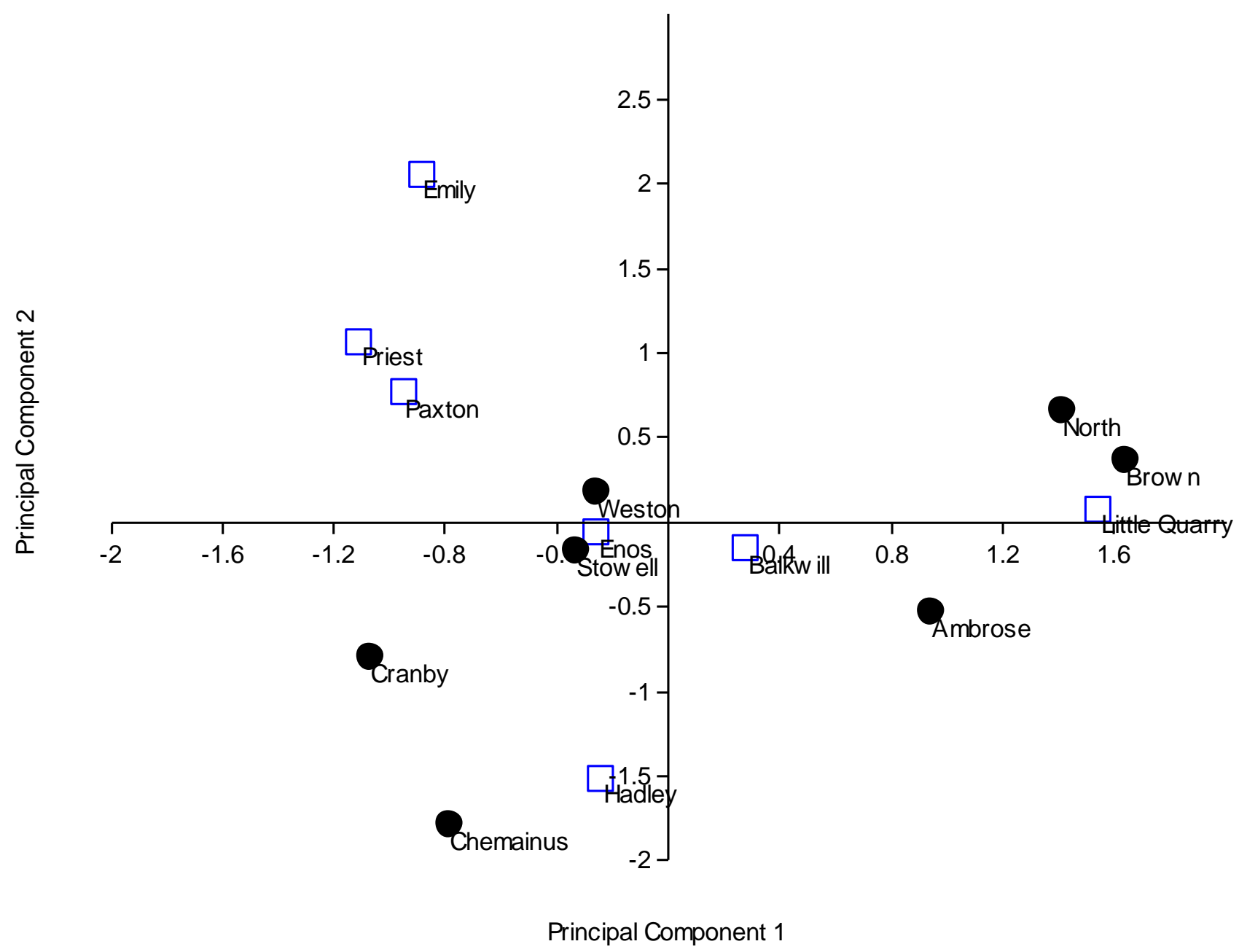

Figure 10. Scatter plot of mean scores along PC1 and PC2 for the principal components analysis of all physical, chemical, and biological variables combined. Principal component 1 and PC2 account for $56.1 \%$ of the total variation, $35.5 \%$ and $20.5 \%$ respectively. Open squares are species pair lakes and filled circles are non-species pair lakes. 


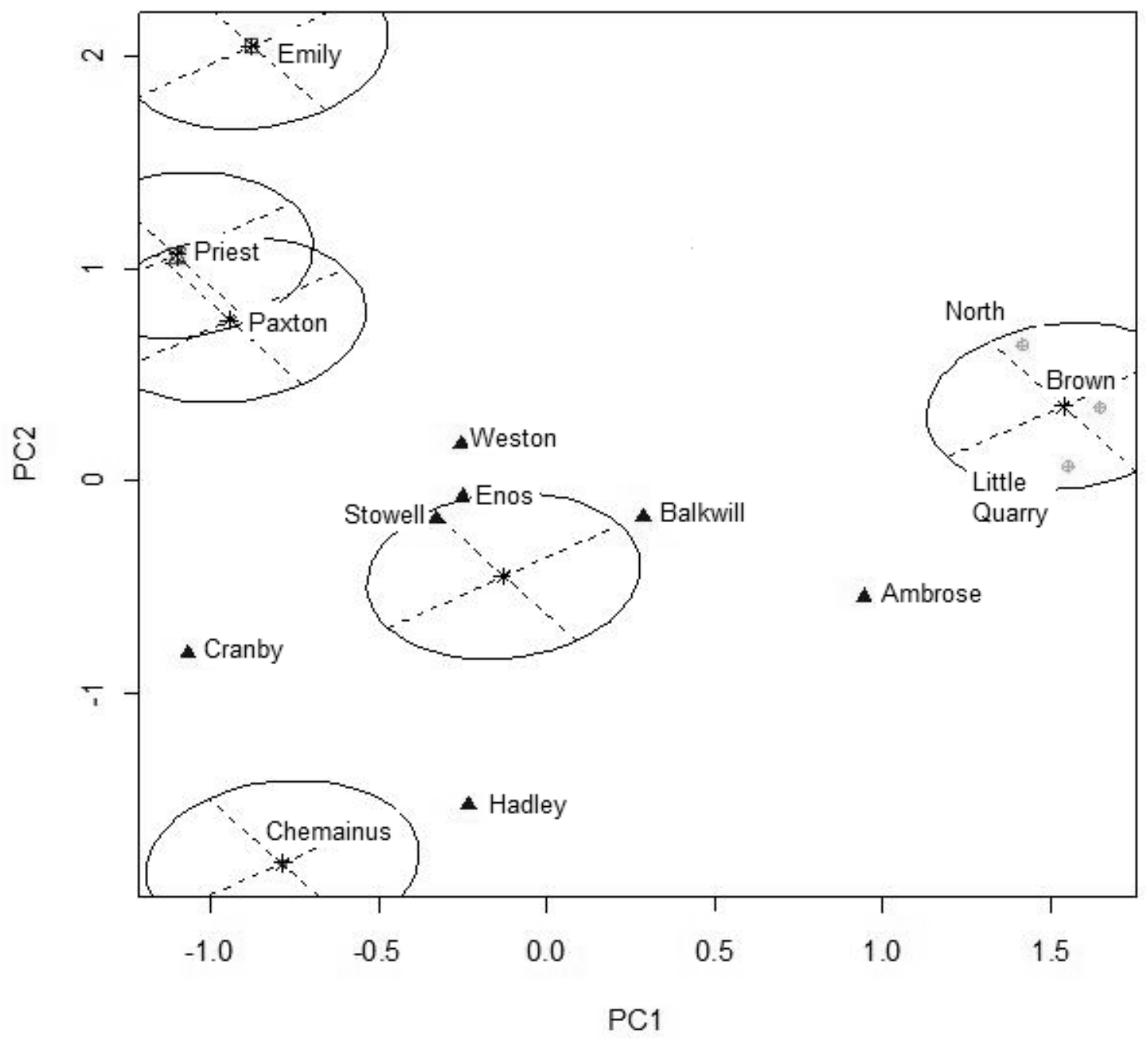

Figure 11. MCLUST analysis of species pair and non-species pair lakes along the principal component one and two axes. Each ellipse has equal variance. Weston, Stowell, Ambrose, Cranby, Enos, Hadley, and Balkwill lakes form one group. North, Brown, and Little Quarry lakes from a second group, Chemainus Lake forms a third group, Paxton Lake forms a fourth group, Priest Lake forms a fifth group, and Emily Lake forms a sixth group. 


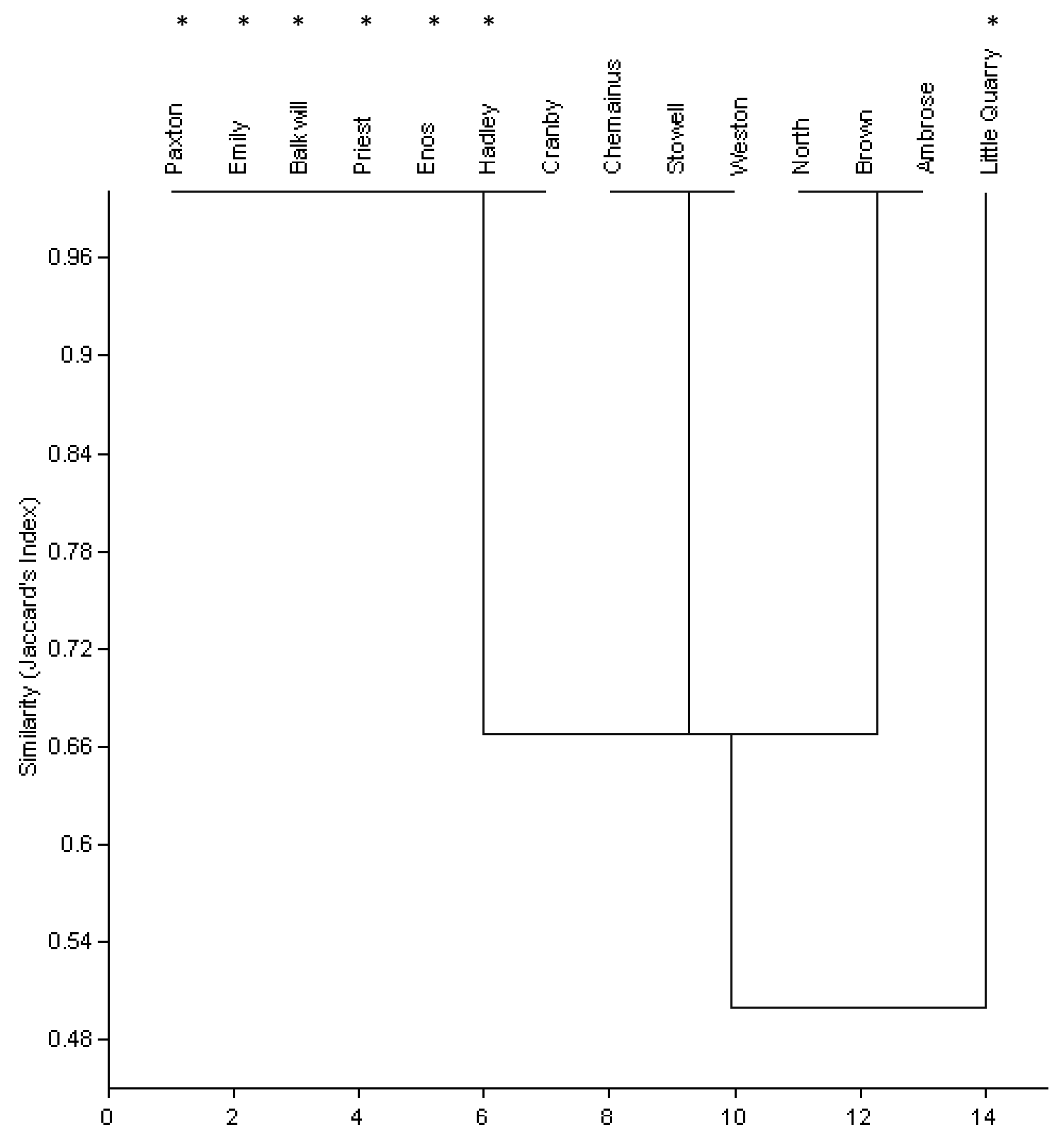

Figure 12. Cluster analysis (single linkage) on fish species composition in SP and NSP lakes using Jaccard's similarity index for presence-absence data. Variables included were threespine stickleback, coastal cutthroat trout, prickly sculpin, and rainbow trout. Species pair lakes are denoted by an '*' while non-species pair lakes are unmarked. 


\section{Literature Cited}

Arnold, M.L. 1997. Natural hybridization and evolution. Oxford University Press, New York, New York, USA.

Allendorf, F.W., R.F. Leary, P. Spruell, and J.K. Wenburg. 2001. The problems with hybrids: setting conservation guidelines. Trends in Ecology and Evolution 16(11): 613-622.

Bassar, R.D., M.C. Marshall, A. Lopez-Sepulcre, E. Zandona, S.K. Auer, J. Travis, C.M. Pringle, A.S. Flecker, S.A. Thomas, D.F. Fraser, and D.N. Reznick. 2010. Local adaptation in Trinidadian guppies alters ecosystem processes. Proceedings of the National Academy of Sciences 107(8): 3616-3621.

Beauchamp, D.A. 1990. Seasonal and diel food habits of rainbow trout stocked as juveniles in Lake Washington. Transactions of the American Fisheries Society 119: 475-482.

Behm, J.E., A.R. Ives, and J.W. Boughman. 2010. Breakdown in postmating isolation and the collapse of a species pair through hybridization. The American Naturalist 175(1): 11-26.

Belant, J.L., K. Kielland, E.H. Follmann, and L.G. Adams. 2006. Interspecific resource partitioning in sympatric ursids. Ecological Applications 16(6): 2333-2343.

Benke, A.C., A.D. Huryn, L.A. Smock, and B. Wallace. 1999. Length-mass relationships for freshwater macroinvertebrates in North America with particular reference to the southeastern United States. Journal of the North American Benthological Society 18(3): 308-343.

Bernatchez, L., A. Chouinard, and G. Lu. 1999. Integrating molecular genetics and ecology in studies of adaptive radiation: whitefish, Coregonus sp., as a case study. Biological Journal of the Linnean Society 68:173-194. 
Blumenshine, S.C., Y. Vadeboncoeur, D.M. Lodge, K.L. Cottingham, and S.E. Knight. 1997. Benthicpelagic links: Responses of benthos to water-column nutrient enrichment. Journal of the North American Benthological Society 16(3): 466-479.

Boughman, J.W. 2001. Divergent sexual selection enhances reproductive isolation in sticklebacks. Nature 411: 944-947.

British Columbia Ministry of Energy Mines and Petroleum Resources. 2004. BCGS Geoscience Map. www.empr.gov.bc.ca/Mining/Geoscience/MapPlace/MainMaps/Pages/default.aspx.

British Columbia Ministry of Environment Ecosystems Branch. 2009. Bathymetric standards for lake inventories. Version 3.0. Resources Information Standards Committee.

British Columbia Ministry of Environment Fisheries Information Data Queries. 2010. Available from http://a100.gov.bc.ca/pub/fidq/main.do [accessed 15 September 2010]. Accessed Sept. 2010.

Brown, L.R., S.A. Mattern, and P.B. Moyle. 1995. Comparative ecology of prickly sculpin, Cottus asper, and coastrange sculpin, C. aleuticus, in the Eel River, California. Environmental Biology of Fishes 42: 329-343.

Bush, G.L. 1994. Sympatric speciation in animals: New wine old bottles. Trends in Ecology and Evolution 9(8): 285-288.

Cairns, J. and R.L. Kaesler. 1969. Cluster analysis of Potomac River survey stations based on protozoan presence-absence data. Hydrobiologia 34(3): 414-432.

Coyne, J.A. and Orr, H.A. 2004. Speciation. Sinauer Associates, Inc., Sunderland, MA.

Culver, D.A., M.M. Boucherle, D.J. Bean, and J.W. Fletcher. 1985. Biomass of Freshwater Crustacean Zooplankton from Length- Weight Regressions. Canadian Journal of Fisheries and Aquatic Sciences 42: 1380-1390. 
Dextrase, A.J. and N.E. Mandrak. 2006. Impacts of alien invasive species on freshwater fauna at risk in Canada. Biological Invasions 8: 13-24.

Diekmann, U. and Doebeli, M. 1999. On the origin of species by sympatric speciation. Nature 400: 354357.

Foote C.J. and P.A. Larkin. 1988. The role of male choice in the assertive mating of sockeye salmon and kokanee, the anadromous and nonanadromous forms of Oncorhynchus nerka. Behaviour 106:4362.

Fraley, D. and A.E. Raftery. 2003 Enhanced software for model based clustering, discriminant analysis and density estimation: MCLUST. Journal of Classification. 20:263-286. http://www.stat.washington.edu/fraley/mclust

Freemark, K.E. and H.G. Merriam. 1986. Importance of area and habitat heterogeneity to bird assemblages in temperate forest fragments. Biological Conservation 36: 115-141.

Futuyma, D. J. and G. Moreno. 1988. The evolution of ecological specialization. Annual Review of Ecology and Systematics 19: 207-233.

Gow, J., C.L. Peichel, and E.B. Taylor. 2006. Contrasting hybridization rates between sympatric threespined sticklebacks highlight the fragility of reproductive barriers between evolutionarily young species. Molecular Ecology 15: 739-752.

Gow, J.L., S.M. Rogers, M. Jackson, and D. Schluter. 2008. Ecological predictions lead to the discovery of a benthic-limnetic sympatric species pair of threespine stickleback in Little Quarry Lake, British Columbia. Canadian Journal of Zoology 86: 564-571.

Grant, P. R. 1994. Ecological character displacement. Science 266 (5186): 746-747.

Grant, P.R. and B.R. Grant. 2002. Unpredictable evolution in a 30-year study of Darwin's Finches. Science 296: 707-711. 
Hammer, Ø., D.A.T. Harper, and P.D. Ryan. 2001. PAST: Palaeontological Statistics software package for education and data analysis. Palaeontological Electronica 4(1): 9

Harmon, L., B. Matthews, S. Des Roches, J.M. Chase, J.B. Shurin, and D. Schluter. 2009. Evolutionary diversification in stickleback affects ecosystem functioning. Nature 458: 1167-1170.

Harrington, L.A., A.L. Harrington, N. Yamaguchi, M.D. Thom, P. Ferreras, T.R. Windham, and D.W. Macdonald. 2009. The impact of native competitors on an alien invasive: temporal niche shifts to avoid interspecific aggression? Ecology 90(5): 1207-1216.

Hatfield, T. and D. Schluter. 1996. A test for sexual selection on hybrids of two sympatric sticklebacks. Evolution 50: 2429-2434.

Hatfield, T. 2001. Status of the stickleback species pair, Gasterosteus spp., in Hadley Lake, Lasqueti Island, British Columbia. Canadian Field Naturalist 115: 579-583.

Hatfield, T. 2009. Identification of critical habitat for sympatric stickleback species pairs and the Misty Lake parapatric stickleback species pair. DFO Can. Sci. Advis. Sec. Res. Doc. No.2009/056

Hendry, A.P., P.R. Grant, B.R. Grant, H.A. Ford, M.J. Brewer, and J. Podos. 2006. Possible human impacts on adaptive radiation: beak size bimodality in Darwin's finches. Proceedings of the Royal Society B 273: 1887-1894.

Hindar, K., and B. Jonsson. 1982. Habitat and food segregation of dwarf and normal Arctic charr (Salvelinus alpinus) from Vangsvatnet Lake, Western Norway. Canadian Journal of Fisheries and Aquatic Sciences. 39: 1030-1045.

Hutchinson, I., T.S. James, P.J. Reimer, B.D. Bornhold, and J.J. Clague. 2004. Marine and limnic radiocarbon reservoir corrections for studies of late- and postglacial environments in Georgia 
Basin and Puget Lowland, British Columbia, Canada and Washington, USA. Quarternary Research 61(2): 193-203.

Jackson, D.A., K.M. Somers, and H.H. Harvey. 1989. Similarity coefficients: Measures of cooccurrence and association or simply measures of occurrence? The American Naturalist 133(3): 436-453.

Jackson, D.A. 1993. Stopping rules in principal components analysis: a comparison of heuristical and statistical approaches. Ecology 74(8): 2204-2214.

Jackson, D.A., P.R. Peres-Neto, and J.D. Olden. 2001. What controls who is where in freshwater fish communities — the roles of biotic, abiotic, and spatial factors. Canadian Journal of Fisheries and Aquatic Sciences 58: 157-170.

Johannesson, K., E. Rolan-Alvarez, and A. Ekendah. 1995. Incipient Reproductive Isolation between Two Sympatric Morphs of the Intertidal Snail Littorina saxatilis. Evolution 49(6): 1180-1190.

Johannesson, K. 2001. Parallel speciation: a key to sympatric divergence. Trends in Ecology and Evolution 16(3): 148-153.

Knight, M.E., G.F. Turner, C. Rico, M.J.H. van Oppen, and G.M. Hewitt. 1998. Microsatellite paternity analysis on captive Lake Malawi cichlids supports reproductive isolation by direct mate choice. Molecular Evology 7: 1605-1610.

Knudsen, R., P. Amundsen, R. Primicerio, A. Klemetsen, and P. Sørensen. 2007. Contrasting nichebased variation in trophic morphology within Arctic charr populations. Evolutionary Ecology Research 9: 1005-1021. 
Kraak, S.B.M., B. Mundwiler, P.J.B. Hart. 2001. Increased number of hybrids between benthic and limnetic threespined sticklebacks in Enos Lake, Canada: the collapse of a species pair. Journal of Fish Biology 58:1458-1464.

Landry, L., W.F. Vincent, L. Bernatchez. 2007. Parallel evolution of lake whitefish dwarf ecotypes in association with limnological features of their adaptive landscape. Journal of Evolutionary Biology 20: 971-984.

Larson, G.L. 1976. Social behaviour and feeding ability of two phenotypes of Gasterosteus aculeatus in relation to their spatial and trophic segregation in a temperate lake. Canadian Journal of Zoology 54: $107-121$.

Lindsey, C.C. 1981. Stocks are chameleons: Plasticity in gill rakers of coregonid fishes. Canadian Journal of Fisheries and Aquatic Sciences 38: 1497-1506.

Losos, J.B., K.I. Warheit, and T.W. Schoener. 1997. Adaptive differentiation following experimental island colonization in Anolis Lizards. Nature 387: 70-73.

Losos, J. B., 2000. Ecological character displacement and the study of adaptation. Proceedings of the National Academy of Science 97(11): 5693-5695.

Lu, G., and L. Bernatchez. 1999. Correlated trophic specialization and genetic divergence in sympatric Lake whitefish ecotypes (Coregonus clupeaformis): support for the ecological speciation hypothesis. Evolution 53: 1491-1505.

Malmquist, H.J., S.S. Snorrason, S. Skulason, B. Jonsson, O.T. Sandlund, and P.M. Jonasson. 1992. Diet differenciation in polymorphic Arctic charr in Thingvallavatn, Iceland. Journal of Animal Ecology 61:21-35.

Manly, B.F.J. 2005. Multivariate statistical methods: a primer. Third edition. Chapman and Hall. 
McPhail, J.D. 1984. Ecology and evolution of sympatric sticklebacks (Gasterosteus): morphological and genetic evidence for a species pair in Enos Lake, British Columbia. Canadian Journal of Zoology 62: $1402-1408$.

McPhail, J.D. 1992. Ecology and evolution of sympatric sticklebacks (Gasterosteus): evidence for a species-pair in Paxton Lake, Texada Island, British Columbia. Canadian Journal of Zoology 70: $361-369$.

McPhail, J.D. 1993. Ecology and evolution of sympatric sticklebacks (Gasterosteus): origin of the species pairs. Canadian Journal of Zoology 71: 515-523.

McPhail, J.D. 1994. Speciation and the evolution of reproductive isolation in the sticklebacks (Gasterosteus) of south-western British Columbia. pp. 188-206. In Bell, M.A., and S.A. Foster (eds.), The evolutionary biology of the threespine stickleback. Oxford Univ. Press, Oxford.

Meyer, A. 1993. Phylogenetic relationships and evolutionary processes in East African cichlid fishes. Trends in Ecology and Evolution 8(8): 279-284.

National Recovery Team for Stickleback Species Pairs. 2007. Recovery Strategy for Paxton Lake, Enos Lake, and Vananda Creek Stickleback Species Pairs (Gasterosteus spp.) in Canada. Species at Risk Act Recovery Strategy Series, Fisheries and Oceans Canada, Ottawa. v + 31 pp.

Nilsson, N.A. and T.G. Northcote. 1981. Rainbow trout (Salmo gairdneri) and cutthroat trout (S. clarki) interactions in coastal British Columbia lakes. Canadian Journal of Fisheries and Aquatic Sciences 38: 1228-1246.

Nosil, P., B.J. Crespi, and C.P. Sandoval. 2002. Host-plant adaptation drives the parallel evolution of reproductive isolation. Nature 417: 440-443. 
Patten, M.A., J.T. Rotenberry, and M. Zuk. Habitat selection, acoustic adaptation, and the evolution of reproductive isolation. Evolution 58(10): 2144-2155.

Pfennig, D.W. and M. McGee. 2010. Resource polymorphism increases species richness: a test of the hypothesis. Philosophical Transactions of the Royal Society 365: 577-591.

Poff, N.L. 1997. Landscape filters and species traits: towards mechanistic understanding and prediction in stream ecology. Journal of the North American Benthological Society 16(2): 391-409.

Pressley, P.H. 1981. Parental effort and the evolution of nest-guarding tactics in the threespine stickleback, Gasterosteus aculeatus. Evolution 35 (2): 282-295.

R Development Core Team (2008). R: A Language and Environment for Statistical Computing.

Reimchen, T.E. 1994. Predators and morphological evolution in threespine stickleback. Pp. 240-276. In Bell, M.A., and S.A. Foster (eds.), The evolutionary biology of the threespine stickleback. Oxford Univ. Press, Oxford.

Rhymer, J.M. and D. Simberloff. 1996. Extinction by hybridization and introgression. Annual Review of Ecology and Systematics 27: 83-109.

Rice, W.R. 1987. Speciation via habitat specialization: the evolution of reproductive isolation as a correlated character. Evolutionary Ecology 1: 301-304.

Ridgway, M.S. and J.D. McPhail. 1984. Ecology and evolution of sympatric sticklebacks (Gasterosteus): mate choice and reproductive isolation in the Enos Lake species pair. Canadian Journal of Zoology 62: 1813-1818

Robinson, B.W. and D.S. Wilson. 1994. Character release and displacement in fishes: A neglected literature. The American Naturalist 144 (4): 596-627. 
Robinson B.W., D.S. Wilson, and A.S. Margosian. 2000. A pluralistic analysis of character release in pumpkinseed sunfish (Lepomis Gibbosus). Ecology 81(10): 2799-2812.

Roff, J.C., and R.R. Hopcroft. 1986. High precision microcomputer based measuring system for ecological research. Canadian Journal of Fisheries and Aquatic Sciences 43: 2044-2048.

Rogers, S. M., V. Gagnon, and L. Bernatchez. 2002. Genetically based phenotype environment association for swimming behavior in Lake whitefish ecotypes (Coregonus clupeaformis Mitchill). Evolution 56:2322-2329.

Rogers S. M. and L. Bernatchez. 2005. Integrating QTL mapping and génome scans towards the characterization of candidate loci under parallel sélection in the Lake whitefish (Coregonus clupeaformis) Molecular Ecology 14(2): 351-361.

Rosenfeld, J. and T. Hatfield. 2006. Information needs for assessing critical habitat for freshwater fish. Canadian Journal of Fisheries and Aquatic Sciences 63: 683-698.

Rosenfeld, J., K. Campbell, E. Leung, and J. Bernhardt. 2008. Effects of alien crayfish on macrophytes and benthic invertebrates in Enos Lake: implications for hybridization of limnetic and benthic stickleback species pairs. Interim Report for BC Forest Science Program Project Y081209.

Sahlen, G., and K. Ekestubbe. 2001. Identification of dragonflies (Odonata) as indicators of general species richness in boreal forest lakes. Biodiversity and Conservation 10: 673-690.

Sample, B.E., R.J. Cooper, R.D. Greer, and R.C. Whitmore. 1993. Estimation of Insect Biomass by Length and Width. American Midland Naturalist 129 (2): 234-240.

Sandlund, O.T., B. Jonsson, H.J. Malmquist, R. Gydemo, T. Lindem, S. Skulason, S.S. Snorrason, and P.M. Jonasson. 1987. Habitat use of artic charr Salvelinus alpinus in Thingvallavatn, Iceland. Environmental Biology of Fishes 20(4): 263-274. 
Scott, W.B., and E.J. Crossman. 1973. Freshwater fishes of Canada. Fish. Res. Board Can., Bull. 184.

Schluter D. and J.D. McPhail. 1992. Ecological character displacement and speciation in sticklebacks. The American Naturalist 140 (1): 85-108.

Schluter, D., and J.D. McPhail. 1993. Character displacement and replicate adaptive radiation. Trends in Ecology and Evolution 8: 197-200.

Schluter, D. 2000. The Ecology of Adaptive Radiation. Oxford University Press, Oxford, UK.

Seehausen, O., J.J.M. van Alphen, F. Witte. 1997. Cichlid fish diversity threatened by eutrophication that curbs sexual selection. Science 277: 1808-1811.

Seehausen, O. 2006. Conservation: Losing biodiversity by reverse speciation. Current Biology 16 (9): 334-337.

Seehausen, O., Y. Terai, I.S. Magalhaes, K.L. Carleton, H.D.J. Mrossos, R. Miyagi, I. Van der Sluijs, M.V. Schneider, M.E. Maan, J. Tachida, H. Imai, and N. Okada. 2008. Speciation through sensory drive in cichlid fish. Nature 455: 620-626.

Skulason, S. and T.B. Smith. 1995. Resource polymorphisms in vertebrates. Trends in Ecology and Evolution 10 (9): 366-370.

Smith, T. B., and S. Skùlason. 1996. Evolutionary significance of resource polymorphisms in fishes, amphibians, and birds. Annual Review of Ecology and Systematics 27: 111-133.

Smock, L. 1980. Relationships between body size and biomass of aquatic insects. Freshwater Biology 10: $375-383$.

Species at Risk Act. 2002. R. S. C., c. 29. s 2 (1). 
Taylor, E.B., and Bentzen, P. 1993. Evidence for multiple origins and sympatric divergence in trophic ecotypes of smelt (Osmerus) in northeastern North America. Evolution 47: 813-832

Taylor, E.B. 1999. Species pairs of north temperate freshwater fishes: evolution, taxonomy, and conservation. Reviews in Fish Biology and Fisheries 9: 299-324.

Taylor, E.B. and J.D. McPhail. 2000. Historical contingency and ecological determinism Interact to prime speciation in sticklebacks, Gasterosteus. Proceedings: Biological Sciences 267 (1460):2375-2384 .

Taylor, E.B., J.W. Boughman, M. Groenenboom, M. Sniatynski, D. Schluter, J.L. Gow. 2006. Speciation in reverse: morphological and genetic evidence of the collapse of a three-spined stickleback (Gasterosteus aculeatus) species pair. Molecular Ecology 15: 343-355.

Todd, T.N., and R.M. Stedman. 1989. Hybridization of ciscoes (Coregonus spp.) in Lake Huron. Canadian Journal of Zoology 67: 1679-1685.

Tonolli, V. 1971. Methods of collection, zooplankton. pp. 1-16. In Edmonson, W.T. and G.G. Winberg (eds.), A manual on methods for the assessment of secondary productivity in fresh waters. Blackwell Scientific Publications Oxford and Edinburgh.

Vamosi, S.M. 2001. The role of predation in the evolution of sympatric stickleback species. Doctoral dissertation, Department of Zoology, The University of British Columbia, Vancouver, B.C.

Vamosi, S.M. 2003. The presence of other fish species affects speciation in threespine sticklebacks. Evolutionary Ecology Research 5: 717-730.

Vamosi, S.M. and D. Schluter. 1999. Sexual selection against hybrids between sympatric stickleback species: evidence from a field experiment. Evolution 53(3): 874-879.

Velema, G.J. 2010. Investigating the role of invasive American signal crayfish (Pacifastiacus leniusculus) in the collapse of the benthic-limnetic threespine stickleback species pair 
(Gasterosteus aculeatus) in Enos Lake, British Columbia. M.Sc. thesis, Department of Zoology, The University of British Columbia, Vancouver, B.C.

Venter, O., N.N. Brodeur, L. Nemiroff, B. Belland, I.J. Dolinsek, and J.W.A.Grant. 2006. Threats to endangered species in Canada. Bioscience 56: 903-910.

Walters, C.J. and F. Juanes. 1993. Recruitment limitation as a consequence of natural selection for use of restricted feeding habitats and predation risk taking by juvenile fishes. Canadian Journal of Fisheries and Aquatic Sciences 50: 2058-2070.

Wetzel, R. G. 2001. Limnology, Saunders: Philadelphia, USA.

Yan, N.D. and G.L. Mackie. 1987. Improved estimation of the dry weight of Holopedium gibberum (Crustacea, Cladocera) using clutch size, a body fat index, and lake water total phosphorus concentration. Canadian Journal of Fisheries and Aquatic Sciences 44: 382-389. 


\section{Appendix A - Environmental variables used in statistical analyses (PCA/DFA) organized as physical, chemical, or biological factors.}

\begin{tabular}{|c|c|c|c|c|c|c|c|c|c|c|c|c|c|c|}
\hline & \multicolumn{7}{|c|}{ Species Pair Lakes } & \multicolumn{7}{|c|}{ Non-Species Pair Lakes } \\
\hline & Balkwill & Emily & Little Quarry & Paxton & Priest & Enos & Hadley & Ambrose & Brown & Chemainus & Cranby & North & Stowell & Weston \\
\hline \multicolumn{15}{|l|}{ Physical } \\
\hline Perimeter (m) & 2268 & 1091 & 2600 & 2277 & 4400 & 1609 & 1130 & 3200 & 1727 & 800 & 3280 & 1737 & 983 & 2117 \\
\hline Relative Littoral Area (\%) & 27.8 & 18.0 & 2.2 & 58.9 & 41.6 & 47.8 & 51.5 & 9.2 & 1.3 & 18.3 & 63.1 & 7.1 & 99.2 & 19.6 \\
\hline Surface Area (m2) & 10.4 & 7.0 & 22.0 & 17.2 & 44.4 & 17.2 & 6.7 & 28.9 & 16.5 & 5.1 & 43.1 & 36.0 & 4.6 & 18.1 \\
\hline Max Depth (m) & 15.8 & 14.5 & 20.8 & 28.7 & 18.0 & 11.9 & 11.7 & 32.8 & 17.6 & 10.0 & 13.3 & 15.6 & 7.2 & 11.8 \\
\hline \multicolumn{15}{|l|}{ Chemical } \\
\hline Chlorophyll a ( $\mu \mathrm{g} / \mathrm{L})$ & 0.6 & 1.2 & 0.9 & 0.8 & 1.7 & 2.9 & 3.3 & 2.1 & $<0.5$ & 4.5 & 3.7 & 0.9 & 1.6 & 1.5 \\
\hline Dissolved Organic Carbon (mg/L) & 6.9 & 4.9 & 3.3 & 5.7 & 6 & 5.4 & 6.4 & 3.5 & 0.7 & 5.1 & 9.1 & 1.7 & 5.1 & 6.1 \\
\hline Alkalinity (Total as CaCO3; mg/L)) & 35 & 110 & 3.7 & 130 & 85 & 47 & 17 & 6.7 & 4.8 & 21 & 47 & 13 & 29 & 31 \\
\hline Total Organic Carbon (mg/L) & 5.7 & 4.9 & 3.2 & 6.5 & 5.8 & 5.7 & 6.7 & 4.7 & 2.2 & 5.5 & 8.3 & 3.2 & 4.9 & 6.1 \\
\hline Coloured Dissolved Organic Matter (Col. Unit) & 10 & 5 & $<5$ & 5 & 5 & 5 & 30 & 5 & 5 & 15 & 10 & 2.5 & 10 & 5 \\
\hline Total Nitrogen (mg/L) & 0.20 & 0.24 & 0.10 & 0.24 & 0.33 & 0.32 & 0.23 & 0.15 & 0.07 & 0.29 & 0.29 & 0.10 & 0.28 & 0.36 \\
\hline Total Phosphorus (mg/L) & 0.006 & 0.005 & 0.004 & 0.010 & 0.006 & 0.006 & 0.007 & 0.007 & 0.004 & 0.009 & 0.011 & 0.005 & 0.007 & 0.009 \\
\hline Total Dissolved Solids (mg/L) & 44 & 160 & 24 & 150 & 150 & 82 & 60 & 24 & 20 & 36 & 74 & 28 & 66 & 60 \\
\hline $\mathrm{pH}$ & 7.91 & 8.18 & 6.70 & 7.70 & 8.30 & 7.82 & 7.18 & 7.30 & 6.75 & 6.80 & 7.53 & 7.10 & 7.56 & 7.34 \\
\hline Conductivity $(\mu \mathrm{S} / \mathrm{cm})$ & 83 & 296 & 25 & 273 & 259 & 148 & 99 & 27 & 21 & 58 & 117 & 43 & 110 & 110 \\
\hline Turbidity (NTU) & -0.02 & -0.15 & -0.29 & 0.16 & 0.18 & 0.27 & 0.33 & 0.32 & -0.21 & 0.36 & 0.28 & -0.70 & -0.13 & -0.23 \\
\hline Water Transparency (k-values) & -0.73 & -0.40 & -0.41 & -0.46 & -0.46 & -0.48 & -1.05 & -0.65 & -0.23 & -0.80 & -0.83 & -0.37 & -0.71 & -0.55 \\
\hline Dissolved Oxygen Epilimnion (\% Sat.) & 96.5 & 94.4 & 99.2 & 90.0 & 94.1 & 92.5 & 92.2 & 98.9 & 95.1 & 76.7 & 96.7 & 108.6 & 92.0 & 100.3 \\
\hline Dissolved Oxygen Hypolimnion (\% Sat.) & 33.8 & 38.1 & 63.2 & 26.9 & 14.0 & 36.3 & 18.6 & 35.1 & 67.9 & 8.7 & 3.5 & 50.3 & 29.9 & 26.9 \\
\hline Dissolved Oxygen Mean (\% Sat.) & 59.2 & 95.5 & 84.1 & 65.4 & 61.7 & 79.8 & 63.7 & 64.7 & 84.3 & 62.9 & 65.4 & 99.2 & 90.8 & 95.6 \\
\hline Temperature Epilimnion $\left({ }^{\circ} \mathrm{C}\right)$ & 21.6 & 22.3 & 22.0 & 22.1 & 22.6 & 23.0 & 22.8 & 22.5 & 21.2 & 22.2 & 22.3 & 21.7 & 22.7 & 23.6 \\
\hline Temperature Hypolimnion $\left({ }^{\circ} \mathrm{C}\right)$ & 6.3 & 8.5 & 5.3 & 7.1 & 8.0 & 8.1 & 5.1 & 4.9 & 7.0 & 7.9 & 8.7 & 6.2 & 8.3 & 7.1 \\
\hline Temperature Mean $\left({ }^{\circ} \mathrm{C}\right)$ & 11.1 & 13.8 & 10.9 & 13.4 & 13.7 & 15.0 & 11.7 & 10.2 & 12.2 & 14.6 & 15.9 & 13.4 & 16.1 & 15.2 \\
\hline
\end{tabular}




\section{Appendix A continued - Environmental variables used in statistical analyses (PCA/DFA) organized as physical, chemical, or biological factors.}

\begin{tabular}{|c|c|c|c|c|c|c|c|c|c|c|c|c|c|c|}
\hline & \multicolumn{7}{|c|}{ Species Pair Lakes } & \multicolumn{7}{|c|}{ Non-Species Pair Lakes } \\
\hline & Balkwill & Emily & $\begin{array}{c}\text { Little } \\
\text { Quarry }\end{array}$ & Paxton & Priest & Enos & Hadley & Ambrose & Brown & Chemainus & Cranby & North & Stowell & Weston \\
\hline \multicolumn{15}{|l|}{ Biological } \\
\hline Zooplankton Biomass $\left(\mathrm{mg} / \mathrm{m}^{3} ; \mathrm{SE}\right)$ & $\begin{array}{c}67.7 \\
(17.1)\end{array}$ & $\begin{array}{l}3168.7 \\
(244.0)\end{array}$ & $\begin{array}{c}1.0 \\
(0.2)\end{array}$ & $\begin{array}{c}2.5 \\
(0.8)\end{array}$ & $\begin{array}{l}175.9 \\
(77.2)\end{array}$ & $\begin{array}{c}8.2 \\
(0.7)\end{array}$ & $\begin{array}{l}38.4 \\
(3.8)\end{array}$ & $\begin{array}{c}2.9 \\
(0.2)\end{array}$ & $\begin{array}{l}15.7 \\
(1.3)\end{array}$ & $\begin{array}{l}21.2 \\
(1.6)\end{array}$ & $\begin{array}{l}22.8 \\
(4.2)\end{array}$ & $\begin{array}{l}15.4 \\
(1.9)\end{array}$ & $\begin{array}{l}100.6 \\
(21.5)\end{array}$ & $\begin{array}{l}346.3 \\
(51.9)\end{array}$ \\
\hline Invetebrate Biomass in Sediment $\left(\mathrm{mg} / \mathrm{m}^{2} ; \mathrm{SE}\right)$ & $\begin{array}{l}3030.1 \\
(757.7)\end{array}$ & $\begin{array}{c}7204.0 \\
(3099.2)\end{array}$ & $\begin{array}{c}949.0 \\
(122.1)\end{array}$ & $\begin{array}{l}3650.7 \\
(864.2)\end{array}$ & $\begin{array}{c}8279.1 \\
(2860.1)\end{array}$ & $\begin{array}{l}1514.5 \\
(393.3)\end{array}$ & 3465.4 & $\begin{array}{l}1193.8 \\
(388.5)\end{array}$ & $\begin{array}{l}2368.2 \\
(427.9)\end{array}$ & $\begin{array}{l}1929.3 \\
(616.9)\end{array}$ & 4192 & $\begin{array}{l}1955.5 \\
(876.2)\end{array}$ & $\begin{array}{c}4069.2 \\
(1708.3)\end{array}$ & $\begin{array}{l}4472.8 \\
(888.1)\end{array}$ \\
\hline Invertebrate Biomass on Rock (mg/m²; SE) & 739.3 & $\begin{array}{l}1600.6 \\
(429.6)\end{array}$ & $\begin{array}{c}291.4 \\
(104.5)\end{array}$ & $\begin{array}{l}1385.5 \\
(307.9)\end{array}$ & $\begin{array}{l}2105.6 \\
(959.4)\end{array}$ & $\begin{array}{l}538.8 \\
(98.2)\end{array}$ & $\begin{array}{l}185.0 \\
(29.3)\end{array}$ & $\begin{array}{c}47.3 \\
(15.5)\end{array}$ & 135.3 & 1157.4 & $\begin{array}{c}871.0 \\
(275.3)\end{array}$ & $\begin{array}{c}557.7 \\
(128.6)\end{array}$ & 1111 & 1482.7 \\
\hline Emergent Macrophyte Coverage (\% of lake SA) & 0.6 & 6.7 & 1.5 & 22.9 & 16.4 & 0.1 & 3.1 & 0.003 & 0.8 & 68.8 & 17.2 & 2.2 & 6.2 & 3 \\
\hline Submergent Macrophyte Coverage (\% of lake SA) & 0.6 & 20.6 & 0.5 & 7.6 & 0.9 & 0.1 & 7.4 & 0.01 & 0.2 & 9.1 & 1.1 & 0.9 & 1.9 & 3.5 \\
\hline Total Macrophyte Coverage (\% of lake SA) & 1.2 & 27.4 & 2 & 30.5 & 17.3 & 0.2 & 10.5 & 0.02 & 0.9 & 77.9 & 18.3 & 3.1 & 8.1 & 6.5 \\
\hline
\end{tabular}




\section{Appendix B - Seasonal ranges of chemical and biological variables for Paxton and Cranby Lakes}

\begin{tabular}{|c|c|c|}
\hline & $\begin{array}{l}\text { Species Pair } \\
\text { Lake }\end{array}$ & $\begin{array}{l}\text { Non-Species } \\
\text { Pair Lake }\end{array}$ \\
\hline & Paxton & Cranby \\
\hline \multicolumn{3}{|l|}{ Chemical } \\
\hline Chlorophyll a ( $\mu \mathrm{g} / \mathrm{L})$ & $0.8-13.8$ & $2.9-3.9$ \\
\hline Dissolved Organic Carbon (mg/L) & $3.2-5.7$ & $4.0-9.1$ \\
\hline Alkalinity (Total as $\mathrm{CaCO} 3 ; \mathrm{mg} / \mathrm{L})$ ) & $130-130$ & $11-47$ \\
\hline Total Organic Carbon (mg/L) & $3.2-6.5$ & $4.4-8.3$ \\
\hline Coloured Dissolved Organic Matter (Col. Unit) & $5-10$ & $10-10$ \\
\hline Dissolved Inorganic Carbon (mg/L) & $29.4-32.5$ & $10.2-11.1$ \\
\hline Total Nitrogen (mg/L) & $0.24-0.38$ & $0.25-0.30$ \\
\hline Total Phosphorus (mg/L) & $0.006-0.012$ & $0.006-0.011$ \\
\hline Total Dissolved Solids (mg/L) & $150-190$ & $74-100$ \\
\hline $\mathrm{pH}$ & $7.4-8.04$ & $6.73-7.53$ \\
\hline Conductivity ( $\mu \mathrm{S} / \mathrm{cm})$ & $273-281$ & $112-117$ \\
\hline Turbidity (NTU) & $-1.51-0.52$ & $-2.72-0.28$ \\
\hline Water Transparency (k-values) & $-0.60--0.46$ & $-0.86--0.64$ \\
\hline Dissolved Oxygen Mean (\% Sat.) & $53.2-96.0$ & $62.1-78.4$ \\
\hline Temperature Mean $\left({ }^{\circ} \mathrm{C}\right)$ & $8.7-13.4$ & $7.9-15.9$ \\
\hline \multicolumn{3}{|l|}{ Biological } \\
\hline Zooplankton Biomass (mg/m3) & $1.0-2.5$ & $0.5-22.8$ \\
\hline Invetebrate Biomass in Sediment $(\mathrm{mg} / \mathrm{m} 2)$ & $3653-6320$ & - \\
\hline Invertebrate Biomass on Rock (mg/m2) & $393.7-1385.5$ & $144.5-871.0$ \\
\hline Emergent Macrophyte Coverage (\%) & $22.5-23.5$ & $0.5-17.2$ \\
\hline Submergent Macrophyte Coverage (\%) & $4.7-7.5$ & $0.01-1.38$ \\
\hline Total Macrophyte Coverage (\%) & $27.2-30.4$ & $0.6-18.3$ \\
\hline
\end{tabular}




\section{Appendix C - Factor loadings for PCA of physical variables}

\begin{tabular}{lcc}
\hline Variable & Axis 1 & \multicolumn{1}{c}{ Axis 2 } \\
\hline Perimeter $(\mathrm{m})$ & -0.6167 & -0.283 \\
Relative Littoral Area (\%) & 0.2232 & -0.8339 \\
Surface Area $(\mathrm{m} 2)$ & -0.577 & -0.3172 \\
Max Depth $(\mathrm{m})$ & -0.4867 & 0.3521 \\
\hline
\end{tabular}




\section{Appendix D - Factor loadings for PCA of chemical variables}

\begin{tabular}{|c|c|c|}
\hline Variable & Axis 1 & Axis 2 \\
\hline Chlorophyll a ( $\mu \mathrm{g} / \mathrm{L})$ & 0.1983 & -0.2962 \\
\hline Dissolved Organic Carbon (mg/L) & 0.3014 & -0.08035 \\
\hline Alkalinity (Total as CaCO3) & 0.2144 & 0.3266 \\
\hline Total Organic Carbon (mg/L) & 0.317 & -0.09547 \\
\hline Coloured Dissolved Organic Matter (Col. Unit) & 0.1127 & -0.3216 \\
\hline Dissolved Inorganic Carbon (mg/L) & 0.2055 & 0.3223 \\
\hline Total Nitrogen (mg/L) & 0.3048 & 0.01946 \\
\hline Total Phosphorus (mg/L) & 0.2551 & -0.1281 \\
\hline Total Dissolved Solids (mg/L) & 0.2296 & 0.3171 \\
\hline $\mathrm{pH}$ & 0.2102 & 0.2695 \\
\hline Conductivity $(\mu \mathrm{S} / \mathrm{cm})$ & 0.2294 & 0.3213 \\
\hline Turbidity (NTU) & 0.2408 & -0.2019 \\
\hline Water Transparency (k-value) & -0.1827 & 0.3493 \\
\hline Dissolved Oxygen Epilimnion (\% Sat.) & -0.1843 & 0.1258 \\
\hline Dissolved Oxygen Hypolimnion (\% Sat.) & -0.3152 & 0.1359 \\
\hline Dissolved Oxygen Mean (\% Sat.) & -0.1609 & 0.2099 \\
\hline Temperature Epilimnion $\left({ }^{\circ} \mathrm{C}\right)$ & 0.1856 & -0.03917 \\
\hline Temperature Hypolimnion $\left({ }^{\circ} \mathrm{C}\right)$ & 0.1984 & 0.1967 \\
\hline Temperature Mean $\left({ }^{\circ} \mathrm{C}\right)$ & 0.1912 & 0.08997 \\
\hline
\end{tabular}




\section{Appendix E - Factor loadings of PCA of biological variables}

\begin{tabular}{lcr}
\hline Variable & Axis 1 & \multicolumn{1}{c}{ Axis 2 } \\
\hline Zooplankton biomass $\mathrm{mg} / \mathrm{m3}$ & 0.3847 & -0.4279 \\
Invetebrate Biomass (Sed) $\mathrm{mg} / \mathrm{m} 2$ & 0.3991 & -0.3769 \\
Invertebrate Biomass (Rock) mg/m2 & 0.4493 & -0.09566 \\
Emergent Macrophyte Coverage (\%) & 0.3211 & 0.6225 \\
Submergent Macrophyte Coverage (\%) & 0.4681 & -0.1138 \\
Total Macrophyte Coverage (\%) & 0.4106 & 0.515 \\
\hline
\end{tabular}




\section{Appendix F - Factor loadings for PCA of all variables combined}

\begin{tabular}{|c|c|c|}
\hline Variable & Axis 1 & Axis 2 \\
\hline Perimeter (m) & -0.01412 & 0.08139 \\
\hline Relative Littoral Area (\%) & -0.1931 & -0.06563 \\
\hline Surface Area (m2) & 0.01613 & 0.0786 \\
\hline Max Depth (m) & 0.08848 & 0.09324 \\
\hline Chlorophyll a ( $\mu \mathrm{g} / \mathrm{L})$ & -0.1509 & -0.2977 \\
\hline Dissolved Organic Carbon (mg/L) & -0.2471 & -0.1075 \\
\hline Alkalinity (Total as $\mathrm{CaCO}$ ) & -0.2193 & 0.2449 \\
\hline Total Organic Carbon (mg/L) & -0.2563 & -0.1274 \\
\hline Coloured Dissolved Organic Matter (Col. Unit) & -0.07791 & -0.2833 \\
\hline Dissolved Inorganic Carbon (mg/L) & -0.2114 & 0.247 \\
\hline Total Nitrogen (mg/L) & -0.2701 & -0.03876 \\
\hline Total Phosphorus (mg/L) & -0.2066 & -0.1683 \\
\hline Total Dissolved Solids (mg/L) & -0.2338 & 0.2446 \\
\hline $\mathrm{pH}$ & -0.1993 & 0.2172 \\
\hline Conductivity $(\mu \mathrm{S} / \mathrm{cm})$ & -0.2342 & 0.2472 \\
\hline Turbidity (NTU) & -0.1796 & -0.2144 \\
\hline Water Transparency (k-value) & 0.1274 & 0.3186 \\
\hline Dissolved Oxygen Epilimnion (\% Sat.) & 0.1709 & 0.1713 \\
\hline Dissolved Oxygen Hypolimnion (\% Sat.) & 0.2667 & 0.1651 \\
\hline Dissolved Oxygen Mean (\% Sat.) & 0.1073 & 0.2036 \\
\hline Temperature Epilimnion $\left({ }^{\circ} \mathrm{C}\right)$ & -0.1511 & -0.05138 \\
\hline Temperature Hypolimnion $\left({ }^{\circ} \mathrm{C}\right)$ & -0.208 & 0.1094 \\
\hline Temperature Mean $\left({ }^{\circ} \mathrm{C}\right)$ & -0.1896 & 0.01197 \\
\hline Zooplankton biomass mg/m3 & -0.08829 & 0.2488 \\
\hline Invetebrate Biomass (Sed) mg/m2 & -0.2046 & 0.2202 \\
\hline Invertebrate Biomass (Rock) mg/m2 & -0.2325 & 0.1906 \\
\hline Emergent Macrophyte Coverage (\%) & -0.1518 & -0.161 \\
\hline Submergent Macrophyte Coverage (\%) & -0.1478 & 0.1169 \\
\hline Total Macrophyte Coverage (\%) & -0.1739 & -0.1091 \\
\hline
\end{tabular}

